\title{
Diferencias de género en la edad del primer matrimonio: \\ Una evidencia desde los modelos de búsqueda marital para Colombia*
}

\section{Gender differences and age at first marriage: \\ Evidence formarital search models for colombian men and women}

Wilmer Javier Ríos Piñerez**

Recibido: 23 de febrero de 2015

Revisado: 16 de marzo de 2015

Aprobado: 2 de febrero de 2016

\section{Resumen}

Este estudio pretende establecer de qué manera la decisión de casarse se ve afectada por un entorno socioeconómico familiar que favorece la acumulación de capital humano y por la transición hacia el rol económico de la adultez. Se evalúa si las diferencias de género en las características de entrada al matrimonio disminuyen a medida que las diferencias en el estatus económico de hombres y mujeres se reducen. Con este propósito,

* Artículo realizado como tesis de grado para optar al título de Magíster en Economía de la Universidad de los Andes. Agradezco a mi asesora, Raquel Bernal Salazar, y a los jurados, Carmen Elisa Flórez y Carlos Medina. Cómo citar este artículo: Ríos, W. J. (2015). Diferencias de género en la edad del primer matrimonio: Una evidencia desde los modelos de búsqueda marital para Colombia.Revista CIFE, 17(27), 149-183.

** Economista, Universidad de Cartagena. Magíster en Economía de la Universidad de los Andes. Docente la Facultad de Economía de la Universidad Católica de Colombia. Correo-e: wj.rios56@uniandes.edu.co 
se estima un modelo de duración de la búsqueda marital para evaluar si estas variables explican la decisión de hombres y mujeres colombianos de casarse o comenzar uniones de hecho a determinada edad. Mayores posibilidades de educación e inserción laboral femenina reducen las diferencias en el comportamiento matrimonial entre hombres y mujeres, generando incentivos a postergar las uniones.

Palabras clave: Mercado matrimonial, búsqueda marital, edad del matrimonio, modelo de duración.

Glasificación JEL: C41, D19, D83.

\begin{abstract}
This study aims to establish how the decision to marry is affected by family socio-economic environment that favors the accumulation of human capital and the economic role transition to adulthood. It also evaluates whether gender differences in the characteristics of entry into marriage decrease as the differences are reduced in the economic status of men and women. To this end, a duration model of marital search is fit to assess whether these variables explain the decision of Colombian men and women to get married or begin de facto unions at a certain age. It is found that higher educational opportunities and job placement reduces the differences in marital behavior between men and women generating, in both cases, incentives to delay marriages as predicted by marital search models.
\end{abstract}

Keywords: Marriage markets, marital search, age at first marriage, duration models.

Classification JEL: C41, D19, D83. 
Diferencias de género en la edad del primer matrimonio: una evidencia desde los modelos de búsqueda marital...

\section{Introducción}

Las teorías económicas de la selección de pareja conciben la decisión de casarse como un resultado de equilibrio del mercado matrimonial. Hombres y mujeres tratan de buscar la mejor pareja posible, sujetos a las restricciones impuestas por el mercado. El equilibrio del mercado matrimonial se caracteriza por la existencia de emparejamiento selectivo como descripción del comportamiento óptimo de individuos que intentan maximizar su utilidad. Ello implica que debería observarse una alta correlación entre el capital humano de esposos y esposas en un mercado matrimonial (Fafchamps y Quisumbing, 2007; Jordán, 2006; Becker, 1973, 1991; Montgomery y Trussell, 1986).

Sin embargo, el efecto de la acumulación de capital humano femenino en la conformación de las familias es objeto de debate entre distintas teorías económicas que explican las uniones matrimoniales. Por una parte, las teorías que se basan en las ventajas comparativas de género explican la división del trabajo dentro del hogar, relacionando los incentivos a unirse en pareja con el nivel de especialización de cada género en el mercado laboral o la economía doméstica. Esta perspectiva predice que mayor educación y participación laboral femenina aumentan la independencia femenina y disminuyen los incentivos para casarse. Por lo tanto, a medida que se mejora el acceso a la educación y al mercado laboral por parte de las mujeres, estos modelos predicen que se debería postergar o eliminar la opción del matrimonio (Becker, 1973, 1977 y 1991).

La característica central de las teorías enfocadas en las diferencias de género es que el beneficio de casarse proviene de la especialización y división del trabajo entre esposos. La tendencia de cada género a especializarse, ya sea en el mercado laboral o en las tareas domésticas, genera una dependencia mutua, en la cual el intercambio de diferentes habilidades es beneficioso para ambos individuos. De aquí surge la predicción acerca de una correlación negativa entre características que son sustitutas, como los salarios.

Por otro lado, para las teorías de búsqueda (Oppenheimer, 1988 y 1997), la decisión de casarse o cohabitar en unión de hecho es resultado de un proceso de búsqueda en el mercado matrimonial, similar a la búsqueda que se realiza en el mercado laboral. Las oportunidades matrimoniales estarían determinadas por la deseabilidad de las características propias y potenciales de las parejas disponibles. En este enfoque, la edad al casarse está asociada con la incertidumbre respecto al desarrollo de las características que definen el rol económico durante la adultez.

Existe una asociación entre las expectativas de un desarrollo laboral favorable y la decisión de casarse. Las mejoras de la posición económica femenina pueden darse conjuntamente con una mayor incidencia del matrimonio, aun cuando podrían tener algún efecto en su postergación. Como resultado genérico, el proceso de conformación de las 
uniones se encuentra muy ligado a la incertidumbre acerca de las características deseables en las parejas disponibles, dadas las características propias.

En los modelos de búsqueda, el emparejamiento selectivo sucede en condiciones de incertidumbre. Por lo tanto, la transición hacia los roles de trabajo adultos de los individuos es una variable que tiene efectos sobre la posibilidad de emparejarse selectivamente. La acumulación de capital humano y la mayor participación laboral de la mujer tienen, entonces, efectos ambiguos sobre la probabilidad de casarse. No obstante, el efecto predicho por Becker, Landes y Michael (1977), la independencia económica femenina, podría aumentar las ganancias del matrimonio y la posibilidad de crear un hogar independiente en menor tiempo según las predicciones de los modelos de búsqueda y emparejamiento selectivo.

A pesar de la fortaleza teórica del Modelo de Diferencias de Género para explicar la división del trabajo en el hogar y los incentivos que genera la decisión matrimonial, algunas observaciones empíricas para Colombia son inconsistentes con esta explicación. Amador, Bernal y Peña (2013) encuentran que el aumento sustancial de la participación laboral femenina colombiana, pasando de cerca del $47 \%$ en 1984 al $65 \%$ en 2006, ha sido precisamente impulsado por las mujeres casadas o en unión libre y de bajo nivel educativo. Al mismo tiempo, la brecha educativa pasó a estar a favor de las mujeres. La proporción de mujeres de mediano y alto nivel educativo pasó de alrededor de 15 y 10 $\%$ al 30 y $28 \%$, respectivamente. Esto sugiere que las inversiones en capital humano y los incentivos a la unión conyugal no son excluyentes, sino complementarios.

No obstante, la brecha salarial a favor de los hombres colombianos es persistente y, a pesar del aumento de la participación laboral de las mujeres, estas se concentran en carreras tradicionalmente femeninas. También siguen teniendo a su cargo la mayor parte de las responsabilidades del hogar. La mejora de las condiciones educativas y laborales de las mujeres colombianas tiene interés por su posible incidencia en las condiciones de las familias y la distribución del bienestar que estas generan entre sus integrantes. Peña et al. (2013), quienes documentan estas desigualdades acumulativas, sugieren que las medidas efectivas para generar la movilidad de la mujer deben incluir la igualdad de oportunidades económicas para hombres y mujeres.

La elección de la edad matrimonial tiene consecuencias económicas importantes para hombres y mujeres. Casarse y tener hijos son decisiones que suelen tener gran incidencia en la vida de las personas. A su vez, se relaciona con las decisiones de educación, trabajo y ahorros. Además, la edad de la primera unión marital define, en gran medida, la edad al momento del nacimiento del primer hijo, lo cual afecta el tiempo y los recursos que se invierten en todos los hijos. 
Diferencias de género en la edad del primer matrimonio: una evidencia desde los modelos de búsqueda marital...

La primera parte de este estudio es la presente introducción. La segunda sección consiste en una revisión de la literatura empírica enfatizando en el vínculo entre estatus económico de la mujer, características de sus parejas potenciales y edad de entrada al primer matrimonio. En el tercer acápite de este estudio se plantea el marco empírico, en el que se caracterizan las variables que inciden en la decisión matrimonial, se presentan los datos y la metodología usados. La cuarta parte expone los resultados. La quinta y última sección concluye.

\section{Revisión de literatura}

El vínculo entre el empleo femenino y el matrimonio no está completamente establecido. La evidencia empírica encuentra dos tipos de influencias del mejor estatus económico de la mujer sobre las oportunidades de matrimonio. Quienes proponen las teorías de la especialización de los roles de género dicen que, en cualquier entorno económico, a mayor participación económica de la mujer, menor es su posibilidad de casarse. Otros investigadores argumentan que, solamente en un entorno en el que los roles de género están altamente diferenciados, existe una relación inversa entre la probabilidad de matrimonio y el estatus económico femenino.

La evidencia empírica internacional es mixta y sugiere que el proceso de desarrollo económico y la incorporación de la mujer a la actividad económica influyen en qué variables y en qué sentido afectan la decisión matrimonial. Boulier y Rosenzweig (1984) utilizan el hecho de la baja participación laboral de las mujeres filipinas para estimar relaciones estructurales entre la edad del matrimonio, el logro escolar y la selección del cónyuge de las mujeres filipinas. Estas variables responden a las condiciones de los mercados matrimoniales, la heterogeneidad individual y la selección marital. El hecho de que la participación laboral femenina sea casi nula permite establecer causalmente que mayores niveles educativos tienen el propósito de "atraer" una pareja con mayor educación y salarios. En este sentido, mayores niveles educativos de la mujer retrasan el matrimonio solo de manera temporal y posteriormente lo aceleran, como predicen los modelos de búsqueda.

Blossfeld y Huinik (1991) analizan cómo los cambios en las inversiones educativas y laborales durante el ciclo de vida influyen en la conformación de las familias alemanas. Para ello, estiman un modelo dinámico de la tasa de riesgo instantáneo de entrada en el matrimonio y la maternidad a partir tanto de características constantes como de las variables en el tiempo. Su resultado principal es que la decisión de entrada al matrimonio es independiente de las inversiones en capital humano y que el matrimonio es pospuesto en respuesta al mayor tiempo de transición hacia la adultez, en términos del tiempo necesario para completar mayores niveles educativos. 
Santow y Bracher (1994) discuten cuál es la relación entre el empleo femenino y el matrimonio. Mientras que las teorías económicas del hogar predicen que el empleo femenino atenúa los incentivos para casarse, en Australia observan que el crecimiento del empleo femenino a partir de los años setenta se debió, por completo, a las casadas. Usando una función de riesgos proporcionales, definida por Cox (1972), encuentran que las mujeres que trabajan incrementan su probabilidad de casarse y que la educación retrasa el matrimonio.

Con esta misma aproximación, encuentran que, para Suecia, los efectos de las variables que explican la formación de uniones son iguales para hombres y mujeres, y que mayor grado de autosuficiencia económica aumenta la probabilidad de unirse (Bracher y Santow, 1998). En ambos casos, se enfatiza en la importancia de incorporar en las estimaciones, el censuramiento muestral y el hecho de que las variables relevantes para la decisión de unirse sean predeterminadas en el momento en que comienza la exposición al riesgo de entrada al matrimonio.

Lewis y Oppenheimer (2000) investigan cómo la composición educativa de los mercados matrimoniales afecta la posibilidad de emparejarse selectivamente y la edad de las uniones. Con el uso del análisis de riesgo competitivo en tiempo discreto, encuentran que las condiciones de los mercados matrimoniales, definidas por la proporción de parejas potenciales con mayores niveles educativos, limitan la posibilidad de emparejarse selectivamente.

Goldstein y Kenney (2001) utilizan una encuesta retrospectiva y un enfoque de máxima verosimilitud para estimar un modelo de difusión logístico que describe la transición del estado civil de solteras a casadas. Estos autores encuentran que las mujeres estadounidenses con grados de educación superior incrementan su probabilidad de estar casadas.

Los estudios sobre modelos de búsqueda marital han tenido poca aplicación para países latinoamericanos. Parrado y Zenteno (2002) estiman una función de riesgos logística para submuestras de hombres y mujeres mexicanos, que incluye características individuales variables y constantes en el tiempo, así como también medidas de las características de los mercados matrimoniales y de los mercados laborales. Sus resultados son consistentes con los modelos de búsqueda marital.

Ono (2003) compara tres escenarios de países industrializados y encuentra que mayores niveles de ingreso disuaden del matrimonio solamente a las mujeres en Japón, donde los roles de género son más diferenciados que en Estados Unidos y Suecia, en donde mayores ingresos alientan el matrimonio.

Manda y Meyer (2005) utilizan un análisis bayesiano para estimar un modelo jerárquico de supervivencia discreta para la edad del primer matrimonio en Malawi. Este modelo permite tener en cuenta explícitamente la heterogeneidad no observada usando efectos 
Diferencias de género en la edad del primer matrimonio: una evidencia desde los modelos de búsqueda marital...

aleatorios con una estructura de correlación. En este caso, el aumento de la edad del matrimonio es producto de una combinación entre los efectos de la educación, del entorno familiar y de la cohorte de nacimiento. Las mujeres con mayores niveles educativos tienen más probabilidad de casarse a edades posteriores que las mujeres con poca o ninguna educación. A su vez, estos autores encuentran diferencias sustanciales entre cohortes en las cuales se observa que las mujeres de cohortes recientes posponen el matrimonio a edades posteriores comparadas con mujeres de cohortes anteriores.

Nobles y Buttenheim (2008) realizan una regresión logística y encuentra que, después de la crisis financiera de 1998, el aumento de los salarios incentivó a que las mujeres y los hombres de Indonesia retrasaran la edad de entrada al matrimonio. Shemyakina (2011), con una regresión de riesgos proporcionales de Cox (1972), encuentra que las mujeres en zonas de conflicto en Tayikistán retrasan el matrimonio en comparación con las residentes en otras zonas del país.

Los estudios para Colombia que han abordado este tema se han enfocado en comprobar si el matrimonio tiene efectos sobre la movilidad social (Jordán, 2006) o si el mercado matrimonial genera incentivos para que las mujeres tengan mayores niveles educativos (Piñeros, 2009). Ninguno de estos estudios establece explicaciones causales porque no tienen en cuenta cómo la dinámica entre las distintas condiciones individuales y los incentivos de los mercados laborales y matrimoniales incide en la decisión de permanecer o no solteros.

Una forma de aproximarse al entendimiento de la decisión de unirse conyugalmente podría ser modelar la probabilidad de que una persona se encuentre casada. Sin embargo, esta aproximación no tiene en cuenta que tal probabilidad está condicionada por la duración que ha tenido la soltería y que, a la vez, el tiempo que las personas permanecen solteras se relaciona con la probabilidad de casarse a cada edad. Por ejemplo, a edades cortas, las personas más educadas pueden tener una baja probabilidad de estar casadas; sin embargo, a edades posteriores, después de que los individuos acumulan educación y mejoran su estatus económico, podrían concretar más rápidamente sus uniones maritales y formar hogares independientes en menor tiempo.

Desarrollar este análisis en el ámbito colombiano es el aporte del presente trabajo. Al utilizar un modelo que explica la duración de la soltería de hombres y mujeres colombianos, se enmarca metodológicamente dentro la literatura internacional de los modelos de búsqueda. Estos modelos relacionan la edad de la primera unión conyugal con las decisiones de acumulación de capital humano, la inserción en el mercado laboral y las características socioeconómicas tanto de los individuos como de sus parejas potenciales.

El propósito principal es establecer si, a medida que las diferencias de género en estas variables disminuyen, también disminuyen las diferencias en las edades de entrada al 
matrimonio o unión de hecho de hombres y mujeres colombianos. En este sentido, una de las preguntas centrales que se pretende responder es cómo se relaciona la edad de la primera unión marital con el estatus económico de las mujeres colombianas y sus potenciales candidatos a ser pareja. La respuesta a esta pregunta se establece en términos de las variables que reflejan el estatus económico familiar, indicadores de la transición hacia la adultez y características de los mercados matrimoniales.

\section{Marco empírico}

\subsection{Un modelo de búsqueda marital}

La característica principal de los modelos de búsqueda marital es que reconocen que adquirir información tiene costos y que los individuos tienen incentivos para asignar recursos, en particular tiempo, a adquirir información acerca de las posibles parejas en lugar de emparejarse aleatoriamente. De manera similar al mercado laboral, en el que una estrategia de búsqueda consiste en fijar un salario de reserva por debajo del cual se rechaza cualquier oferta de trabajo, un individuo en un mercado matrimonial puede establecer un conjunto de parejas "elegibles" a partir del cual selecciona al cónyuge. Esta selección se realiza a partir de características que maximizan la utilidad neta del proceso de búsqueda (Oppenheimer, 1988; Boulier y Rosenzweig, 1984).

Un resumen de lo que sería dicha estrategia es el siguiente (Tenjo, Misas, Contreras y Gaviria, 2012):

Sea $u$ una variable que resume las características que determinan la utilidad de emparejarse con un individuo determinado y sea $(u)$ la función de densidad que describe la percepción del individuo de lo que es la distribución de parejas potenciales en un momento determinado. A su vez, $\mu$ y $\sigma$ son la media y la desviación estándar de la distribución ().

Los individuos fijan una utilidad de reserva $\mathrm{V}$ y establecen la siguiente regla de decisión:

Si $u \geq V$, se casa.

Si $u<\mathrm{V}$, permanece soltero.

Dado lo anterior, la probabilidad de que un individuo permanezca soltero sería:

$$
\operatorname{Prob}(u<V)=G(V)=\int_{0}^{V} g(u) d u
$$

La probabilidad de que un individuo se case sería:

$$
\operatorname{Prob}(u \geq V)=1-G(V)=1-\int_{0}^{V} g(u) d u
$$


Diferencias de género en la edad del primer matrimonio: una evidencia desde los modelos de búsqueda marital...

Si se supone que los emparejamientos potenciales son un proceso aleatorio, el valor esperado del número de parejas que se encontrarían antes de que una sea aceptable, dado por $L$, se expresa como:

$$
D=E(L)=\frac{1}{1-G(V)}=\frac{1}{1-\int_{0}^{V} g(u) d u}
$$

Si se supone que el individuo conoce una pareja potencial por periodo, $D$ se puede interpretar como la duración esperada de la búsqueda. Si este supuesto no se cumple, entonces la duración de la búsqueda sería una función de $D$.

La utilidad esperada que obtendría el individuo cuando decida unirse se puede expresar como:

$$
U_{E}=E(u \mid u \geq V)=\frac{\int_{V}^{\infty} u g(u) d u}{1-G(V)}=\frac{\int_{V}^{\infty} u g(u) d u}{1-\int_{0}^{V} g(u) d u}
$$

La utilidad de reserva se establece maximizando el valor presente del beneficio neto esperado de la búsqueda. A su vez, la búsqueda tiene costos directos y de oportunidad. Los costos directos son los asociados con la búsqueda misma, como la adquisición de información y la generación de ofertas. Los costos de oportunidad están asociados con la utilidad que deja de percibir el individuo por dedicar su tiempo a la búsqueda en lugar de emparejarse. En general, los costos directos se pueden considerar como fijos por periodo, pero el costo de oportunidad crece con la duración de la búsqueda. Si suponemos que se recibe una oferta por periodo, podemos expresar los costos $(C)$ como una función de la duración misma de la búsqueda:

$$
C=F D+h(D)=C(V) \quad y \quad \frac{\partial C}{\partial V}>0
$$

En la ecuación, $F$ representa el costo fijo directo por periodo, $h$ es el costo de oportunidad que es función de la duración de la búsqueda.

El individuo determina su utilidad de reserva óptima maximizando el valor presente del beneficio neto $(B(V))$ de la búsqueda, teniendo un horizonte de planeación $T$ dado por la siguiente función:

$$
\begin{gathered}
B(V)=\int_{D}^{T} V e^{-\rho t} d t-\int_{0}^{V} C(V) e^{-\rho t} d t \\
B(V)=\frac{1}{\rho}\left[V\left(e^{-\rho D}-e^{-\rho T}\right)-C(V)\left(1-e^{-\rho D}\right)\right]
\end{gathered}
$$

El valor óptimo de la utilidad de reserva $V^{*}$ se obtiene resolviendo:

$$
\frac{\partial B(V)}{\partial V}=0
$$

Esto equivale a igualar el beneficio marginal con el costo marginal de búsqueda. La utilidad de reserva óptima es una función de la distribución de posibles parejas, la tasa de descuento y el horizonte de la toma de decisiones. 
ISSN: 0124-3551 / Año 17, No 27 / julio-diciembre / pp. 149-183

$$
V^{*}=v(g(u), \rho, T)
$$

Una vez determinada la utilidad de reserva óptima, también se define la duración óptima de la búsqueda $D^{*}$, de forma que:

$$
D^{*}=d(g(u), \rho, \mathcal{N})
$$

La tasa de descuento $\rho$ es una medida del costo intertemporal de la búsqueda de pareja. Esta medida se relaciona inversamente con los recursos disponibles por el individuo y su familia. Las redes y calidad de contactos aumentan cuando hay más ingresos y educación familiar. Por lo tanto, la duración de la búsqueda aumenta cuando el individuo proviene de una familia con mayores ingresos y nivel educativo porque tiene más recursos para financiar su búsqueda.

El ingreso y el estatus socioeconómico familiar tienen dos efectos: uno directo, que se da por medio de la tasa de descuento, pues reduce los costos intertemporales de búsqueda y mejora las oportunidades para seguir buscando parejas deseables; y otro indirecto, que consiste en proporcionar características que mejoran las parejas potenciales, tales como la educación; es decir, la riqueza familiar aumenta indirectamente $\mu$ por medio de la mejora de las aspiraciones acerca de la pareja, aumentando la utilidad de reserva y la duración óptima de la búsqueda.

La función de densidad $(u)$, que es la distribución de parejas potenciales en un momento determinado, es función de características propias que atraen parejas de mejor "calidad" o que mejoran las parejas potenciales. Es decir, la media y la desviación estándar de esta distribución son diferentes en individuos con características diferentes, pero también en mercados matrimoniales diferentes. Así, $\mu$ y $\sigma$, la media y la desviación estándar de la distribución ( ), resumen características diferenciales de los mercados matrimoniales a que se enfrenta un individuo, dadas sus características.

En una situación de emparejamiento selectivo, los hombres y las mujeres con niveles educativos por encima del promedio de su género buscarán emparejarse con mujeres y hombres de nivel educativo también superior al promedio de su género, por lo que estarían dispuestos a posponer las uniones hasta encontrar la pareja que cumpla con el nivel educativo esperado. Es decir, los hombres y las mujeres más educados tienen una utilidad de reserva mayor, por lo que la duración óptima de su búsqueda también la tiene. Sin embargo, si estos mismos hombres y mujeres se encuentran en un mercado matrimonial distinto, en el que los niveles de educación femeninos son poco variables y bajos, entonces tienen expectativas menores sobre el nivel educativo de sus posibles parejas y, por lo tanto, una duración óptima menor.

Lewis y Oppenheimer (2000) encuentran evidencia de que los individuos residentes en zonas con mercados matrimoniales menos favorables tienden a casarse con personas 
de menor nivel educativo y que tal tendencia se incrementa a medida que su edad aumenta. La desviación estándar, entonces, refleja la percepción de la variabilidad de las características de las posibles parejas. Las condiciones de los mercados matrimoniales determinan la distribución de las características relevantes para el emparejamiento selectivo, en particular, la escasez y la dispersión de las características deseables. Los individuos posponen la decisión matrimonial mientras perciben que sus parejas potenciales mejoran, y aceleran la decisión cuando no lo hacen.

La finalización de los estudios y la entrada al mercado laboral determinan la finalización de la transición al rol económico adulto. A partir de que se completa esta transición, es de esperarse que, en términos de parejas potenciales, los beneficios de seguir soltero dejen de aumentar. Mientras tanto, los costos de oportunidad continúan creciendo, ya que el número de parejas potenciales va disminuyendo con el paso del tiempo porque estas se van casando. Por esta razón, los individuos demoran el matrimonio antes de finalizar la transición y aceleran la decisión cuando esta se completa. Los individuos que postergan la decisión matrimonial una vez finalizada la transición se enfrentan, cada vez más, a escasez de posibles parejas y, por ende, a menores posibilidades de abandonar la soltería.

\subsection{Los datos}

La información utilizada para los ejercicios de estimación son los del primer corte transversal de la Encuesta Longitudinal de Hogares realizada por la Universidad de los Andes (ELCA) en 2010. La ELCA contiene información de las características socioeconómicas y antecedentes familiares de jefes de hogar y sus cónyuges, así como antecedentes familiares y datos retrospectivos de eventos, tales como la primera unión marital, las características de los padres y el primer empleo. Los datos acerca de las características del mercado laboral y las características demográficas que influencian los mercados matrimoniales se consultaron en la compilación de estadísticas históricas económicas y sociales realizada por el Departamento Nacional de Planeación (DNP) a partir de las encuestas de hogares realizadas por el DANE desde 1976. El nivel de agregación de estos datos es nacional.

La población bajo riesgo está conformada por hombres y mujeres entre $14^{1}$ y 40 años de $\operatorname{edad}^{2}$ que no han tenido uniones anteriores, ya que el evento de interés es el primer

1 Según lo estipulado en el Código Civil colombiano, a partir de que se tiene la edad de catorce años, una persona puede celebrar contrato de matrimonio con el permiso de sus tutores legales. (Art. 117, Código Civil colombiano).

2 Al usar la información de la población entre 14 y 40 años en un momento en el tiempo y estimar funciones de supervivencia en el estado de soltería, se utiliza la información de un corte transversal para construir un comportamiento a lo largo de la vida de una cohorte hipotética. En tal sentido, se asume que las cohortes de edad más jóvenes se comportan como las de mayor edad en cuanto a la primera unión por edad, mortalidad selectiva, migración selectiva, entre otros aspectos que podrían afectar la permanencia en la soltería. A fin de verificar la robustez de los resultados en la sección de anexos, se incluye una evaluación de los resultados por cohortes de edad. 
matrimonio o unión de hecho. Como las preguntas de la encuesta se realizan sobre jefes de hogar y sus cónyuges al momento de la encuesta, no es posible, a partir de los datos, recuperar la edad de la primera unión para personas viudas, separadas y vueltas a unir. Tal situación reduce la representatividad de los resultados, pues estos quedan condicionados al subconjunto de la población con uniones más estables.

Lehrer (2006) y Becker, Landes y Michael (1977) encuentran evidencia de que la estabilidad del matrimonio está positivamente relacionada con las ganancias de este.

Por otra parte, para el análisis descriptivo se tomó la población urbana y rural. Sin embargo, para la estimación de los modelos de duración se incluyeron únicamente a los individuos residentes en zonas urbanas porque solamente para estos se dispone de variables del mercado laboral.

Uno de los problemas empíricos más importantes de la estimación de los modelos de duración es ordenar temporalmente las variables. La mayoría de las características individuales son observadas al momento de la encuesta, por lo que contienen las consecuencias de las decisiones anteriores, entre ellas la de la unión marital. En este sentido, resulta difícil establecer el orden causal entre la situación matrimonial y el comportamiento económico. A su vez, las variables de los individuos residentes en un área específica reflejan procesos ocurridos durante periodos indefinidos que pudieron ocurrir en áreas diferentes a donde se recolecta la información. El problema potencial es que, entonces, los efectos por área de residencia podrían no ser exógenos. Si los individuos escogen conjuntamente su estatus marital y su zona de residencia basándose en variables no observadas, como el deseo de emparejarse con individuos con las características existentes en esa comunidad, se sobreestimaría el efecto de las condiciones de las variables locales en la decisión matrimonial (Angrist, 2002).

También sucede si escogen su estatus laboral o los niveles educativos al mismo tiempo que se toma la decisión de permanecer soltero o casarse. Peña (2006) y Piñeros (2009) señalan que las decisiones educativas de las mujeres colombianas son consistentes con incentivos proporcionados por los mercados matrimoniales y con la mejora de la distribución del bienestar en los hogares. Si el nivel de inversión en educación de los individuos responde a los incentivos del mercado matrimonial, entonces el nivel de educación escogido por los individuos es endógeno.

A fin de minimizar estos problemas, se utilizaron como variables explicativas tres grupos de variables que, en mayor o menor medida, son predeterminadas al momento de la decisión de unirse. El primer grupo es el estatus socioeconómico de los padres de individuos de la muestra de interés, medido con base en variables binarias que indican si el padre o la madre tienen algún año de educación universitaria. También se incluye como variable de control si el individuo vivía con personas o familiares diferentes a los padres 
Diferencias de género en la edad del primer matrimonio: una evidencia desde los modelos de búsqueda marital...

a los 14 años de edad. El segundo grupo de regresores se refiere a las características de los mercados matrimoniales. Los factores demográficos condicionan la selección marital y definen las características de los mercados matrimoniales porque la abundancia o escasez de parejas disponibles disminuye o aumenta la dificultad de encontrar pareja. Para las mujeres, se utiliza el número de hombres en la cohorte de 15 a 20 años de edad, por cada 100 mujeres en la misma cohorte de edad en el departamento de residencia a los 14 años de edad. Para los hombres, se utiliza el número de mujeres en la cohorte de 15 a 20 años de edad, por cada 100 mujeres en la misma cohorte de edad en el departamento de residencia a los 14 años de edad.

Así mismo, se incluyen medidas de la situación económica relativa de las mujeres con respecto a los hombres a nivel nacional y en el año cuando cada individuo tenía 14 años de edad. El porcentaje de mujeres en el total de la fuerza laboral colombiana es medido como $p_{f} / p_{f}+p_{m} \times 100$, donde $p_{f}$ es el número de hombres empleados y $p_{m}$ es el número de mujeres empleadas. La brecha salarial de mujeres a hombres medida como los salarios relativos es $W_{f} / W_{m} \times 100$, donde $W_{f}$ y $W_{m}$ son los salarios nominales promedio, a nivel nacional, de mujeres y hombres, respectivamente.

El tercer grupo está compuesto por los indicadores de transición hacia el rol económico adulto. La adultez se encuentra determinada por la terminación de los estudios, la entrada al mercado laboral y los salarios iniciales. Las medidas utilizadas para el análisis son el número de años transcurridos desde que el individuo dejó o terminó sus estudios y el número de años transcurridos desde que el individuo trabajó por primera vez. Estas variables de transición tienen cierto nivel de carácter endógeno derivado del hecho de que, a pesar de que para una parte de la población están predeterminadas, para otra no lo están. Tanto la decisión de dejar los estudios como la de empezar a trabajar podrían tener algún grado de simultaneidad con la decisión de permanecer soltero ${ }^{3}$. Además, se incluyen variables dicotómicas que indican la participación laboral y si el salario inicial fue inferior, igual o superior al salario mínimo legal.

\subsection{Estrategias de estimación}

El objetivo econométrico es determinar cuántos años permanecen solteros los individuos. La variable de duración (i.e. la edad al casarse) se encuentra censurada, puesto que para los individuos solteros al momento de la encuesta no se sabe cuánto tiempo más permanecerán en ese estado. La censura genera problemas de sesgo al subestimar indicadores del tiempo de búsqueda (p. ej.: la media y la mediana) porque solo se observan para quienes ya se han unido. Para corregir este problema, se establece una especificación en la que se

3 Estas variables toman el valor de 0 para los individuos que se encontraban estudiando al momento de la encuesta y para quienes continuaron estudiando después de unirse. De manera análoga, se calculó para el tiempo desde la entrada a trabajar. Por lo tanto, la simultaneidad (y el carácter endógeno) de la decisión es más severa para quienes deciden contemporáneamente suspender los estudios y unirse (o empezar a trabajar y unirse). 
incluye la información acerca de si los individuos terminaron su búsqueda o si continúan en esta, con el fin de obtener estimadores consistentes de la duración.

Si se define la variable aleatoria $T$ como el tiempo transcurrido en años de la vida del individuo hasta su primera unión, la probabilidad de que la edad del primer matrimonio sea menor a un valor particular $t$ se puede definir mediante una función de distribución acumulada definida como:

$$
P(T \leq t)=F(t)=\int_{0}^{t} f(s) d s
$$

A partir de esta función puede obtenerse la función de supervivencia que hace referencia a la probabilidad de exceder dicho valor:

$$
S(t)=P(T>t)=1-F(t)=1-\int_{0}^{t} f(s) d s
$$

La probabilidad instantánea de cambio de soltero a casado condicional a haber estado soltero hasta la edad t puede obtenerse a partir de estas definiciones. Dicha probabilidad se conoce como tasa de riesgo $\mathrm{h}(\mathrm{t})$ y se expresa así:

$$
h(t)=\lim _{\Delta t \rightarrow 0} P(t \leq T \leq t+\Delta t \geq t)=\frac{f(t)}{S(t)}
$$

La función de supervivencia y la de riesgo están íntimamente ligadas. En este estudio se usan dos tipos de análisis empírico. Primero, como análisis descriptivo, la estimación no-paramétrica de funciones de supervivencia mediante el estimador de Kaplan-Meier. El segundo análisis corresponde a la estimación paramétrica del tiempo de búsqueda, dadas las variables explicativas propuestas en el modelo teórico y en la revisión de literatura. Para ello, se utiliza un modelo de tiempo de fallo acelerado (ATF) distribuido log-logístico.

Los análisis descritos son complementarios. Kaplan-Meier permite observar cómo es la evolución de los datos de supervivencia, en términos del porcentaje de supervivientes, a medida que pasa el tiempo. La ventaja de los enfoques no-paramétricos es que evitan tener que suponer que los datos siguen una distribución de probabilidad específica, por lo que son más flexibles y evitan la pérdida de información producto de la estimación de parámetros. Por otro lado, permite hacerse una idea de si los datos se ajustan a un modelo de tiempo de fallo acelerado y cómo se comporta el riesgo de fallo a medida que pasa el tiempo. Cuando las funciones de supervivencia estimadas con Kaplan-Meier no son paralelas, las proporciones de riesgo aumentan o disminuyen en el tiempo. El modelo de tiempo de fallo acelerado (ATF) distribuido log-logístico es útil para incorporar este hecho; a diferencia de otras distribuciones utilizadas para la estimación paramétrica de la duración ${ }^{4}$, permite que la probabilidad de que un individuo se case en el periodo $t$

4 Estas variables toman el valor de 0 para los individuos que se encontraban estudiando al momento de la encuesta y para quienes continuaron estudiando después de unirse. De manera análoga, se calculó para el tiempo desde la 
Diferencias de género en la edad del primer matrimonio: una evidencia desde los modelos de búsqueda marital...

(en años) -dado que no ha estado casado $t^{-1}$ años-, es decir, la tasa instantánea de riesgo, dada por $h(t)$, sea creciente o decreciente a medida que pasa el tiempo. Se explica a continuación en qué consiste cada procedimiento.

\subsubsection{La estimación no-paramétrica del tiempo de búsqueda marital}

El estimador de Kaplan-Meier corrige el sesgo originado por la censura de la muestra sin tener que suponer una distribución de probabilidad para los datos. La supervivencia estimada está dada por:

$$
\hat{S}(t)=\prod_{t_{(i)}-t} \frac{n_{i}-d_{i}}{n_{i}}
$$

En la ecuación, $n_{i}$ corresponde al número de individuos en riesgo de cambio de estado al momento $t_{(i)}$ y $d_{i}$ es el número de cambios de estado observados al momento $t_{(i)}$. La variable de censura $c_{i}$ caracteriza a cada individuo de la muestra. Cuando $t>t(i)$, entonces, $S(t)=1$.

\subsubsection{El modelo de tiempo de fallo acelerado (ATF) distribuido log-logístico}

Los modelos de fallo acelerado (ATF) centran su atención en el logaritmo natural del tiempo de supervivencia, expresado como una función lineal de las variables explicativas teniendo un modelo lineal dado por:

$$
\log t i=X i \beta+\varepsilon i
$$

En la ecuación, $X i$ es un vector de variables explicativas, $\beta$ es un vector de coeficientes de regresión y $\varepsilon i$ es el término de error con una función de densidad (). De la forma en que se modele el error dependerá el modelo de regresión que se obtiene. En este caso se utilizará la distribución log-logística porque permite tener tasas de riesgo de comportamiento nomonótono, en particular, inicialmente crecientes y después decrecientes. Otras distribuciones usadas para estimar modelos ATF, como las de Weibull o Gompertz, implican tasas de riesgo crecientes o decrecientes durante todo el tiempo de búsqueda.

Las funciones de densidad y supervivencia log-logísticas están dadas por:

$$
\begin{gathered}
f(t)=\frac{\lambda^{\frac{1}{\gamma}} t^{\frac{1}{\gamma}-1}}{\gamma\left[1+(\lambda t)^{\frac{1}{\gamma}}\right]^{2}} \\
S(t)=\left[1+(\lambda t)^{\frac{1}{\gamma}}\right]^{-1}
\end{gathered}
$$

entrada a trabajar. Por lo tanto, la simultaneidad (y el carácter endógeno) de la decisión es más severa para quienes deciden contemporáneamente suspender los estudios y unirse (o empezar a trabajar y unirse). 
La función de riesgo es:

Donde,

$$
\begin{gathered}
h(t)=\frac{f(t)}{S(t)}=\frac{\lambda^{\frac{1}{\gamma}} t^{\frac{1}{\gamma}-1}}{\gamma\left[1+(\lambda t)^{\frac{1}{\gamma}}\right]^{\mathrm{m} !}} \\
\lambda_{i}=e^{-X i \beta}
\end{gathered}
$$

El parámetro $\gamma$ se refiere a la forma de la distribución log-logística. Si $\gamma \geq 1$, el riesgo es monótonamente decreciente. Cuando $\gamma<1$ es creciente y luego decreciente a medida que pasa el tiempo. Esto tiene implicaciones para las conclusiones de este estudio. Una de las preguntas centrales de este trabajo es si postergar las uniones a edades tempranas disminuye la posibilidad de concretar las uniones posteriormente. Si el riesgo es monótonamente creciente, entonces, a medida que el tiempo pasa, la probabilidad de encontrar pareja aumenta. A su vez, si existe una región donde el riesgo es decreciente, quienes posterguen el matrimonio más allá de cierta edad tienen cada vez menos probabilidades de concluir su soltería. La interpretación de los coeficientes $\beta$ de la regresión log-logística es directa. El aumento de 1 unidad de la variable explicativa aumenta en $100 \times \beta$ por ciento el tiempo que una persona permanece soltera.

\section{Resultados}

\subsection{Resultados del análisis no-paramétrico del tiempo de búsqueda marital}

La estimación no paramétrica de las funciones de supervivencia se realiza usando el estimador de Kaplan-Meier. Esta función escalonada decreciente indica la probabilidad de permanecer soltero (eje $Y$ ) hasta cierta edad (eje $X$ ).

\subsubsection{Hombres y mujeres por zona de residencia}

La figura 1 presenta la función de supervivencia para hombres y mujeres que residían a los 14 años en áreas rurales y urbanas. Las mujeres comienzan a unirse (mediante matrimonio o unión de hecho) más jóvenes que sus parejas. La edad mediana, aquella en la que el $50 \%$ de las mujeres se ha unido, es 20 años. A pesar de que la soltería más larga es de 47 años, las mujeres tienen una probabilidad del $95 \%$ de haberse unido antes de cumplir 30 años. A su vez, se destaca que la cuarta parte de las mujeres ya se ha unido antes de su mayoría de edad (18 años). En el caso de los hombres, la edad mediana es 25 años (5 años más que las mujeres). Hasta los 45 años, la probabilidad de los hombres de permanecer solteros es menor al $5 \%$, y es la edad en la que se espera que todas las mujeres hayan tenido la primera unión marital. 
Diferencias de género en la edad del primer matrimonio: una evidencia desde los modelos de búsqueda marital...

Los hombres tienen un comportamiento homogéneo en la edad al casarse, mientras que las mujeres residentes en zonas urbanas tienden a unirse a mayor edad que las de zonas rurales. La edad mediana en zonas rurales es alrededor de dos años menor que la edad mediana de las mujeres residentes en zonas urbanas. De esta forma, las diferencias entre las edades de la primera unión son menores entre hombres y mujeres residentes en zonas urbanas en comparación con las diferencias en la edad de la primera unión de hombres y mujeres en zonas rurales. En la figura 1 se observa cómo la función de supervivencia de las mujeres residentes en zonas urbanas (línea amarilla) se encuentra más cerca de la función de supervivencia de los hombres (líneas azul y roja).

Figura 1. Funciones de supervivencia por sexo y zona de residencia a los 14 años.

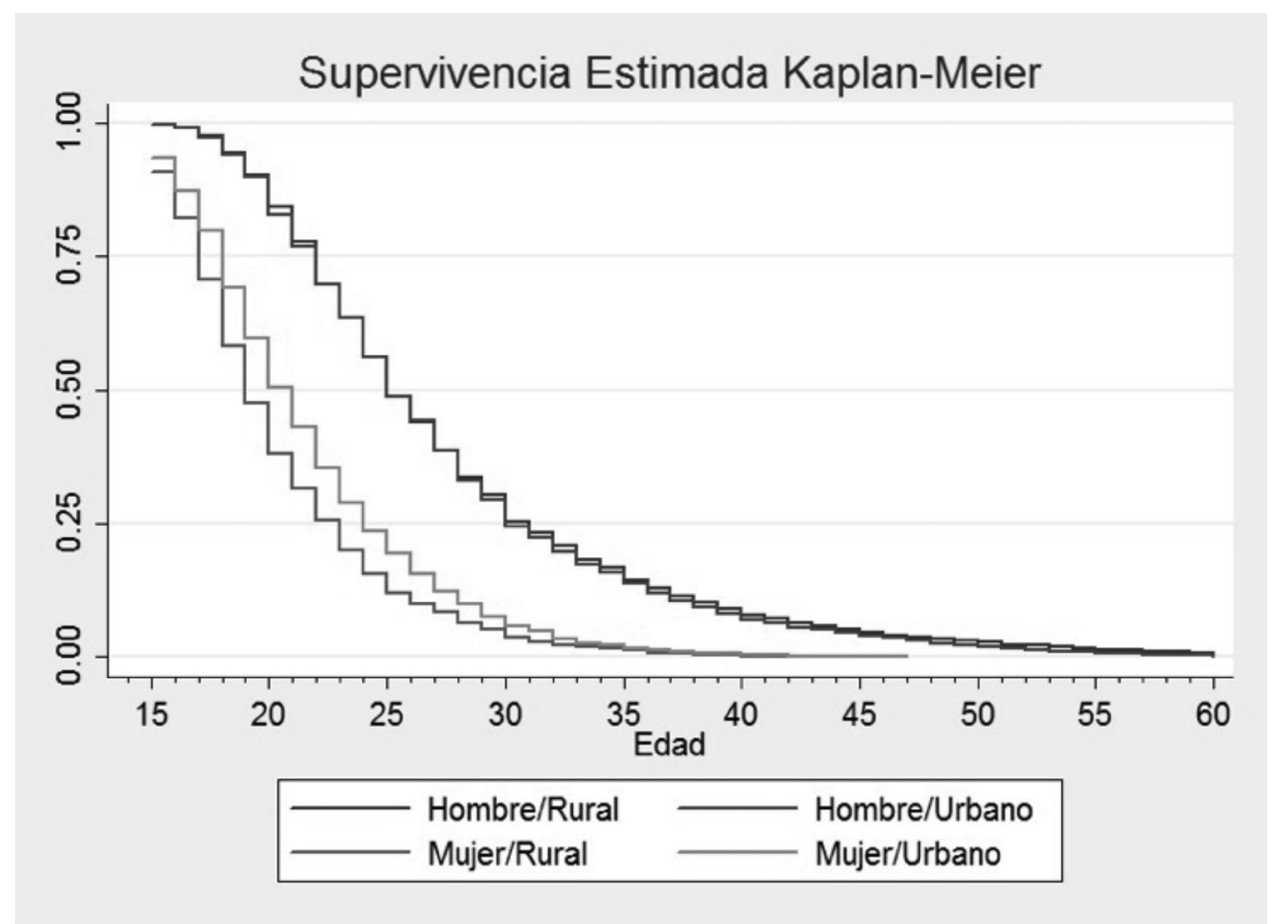

Fuente: Elaboración propia a partir de la ELCA 2010.

\subsubsection{Educación}

En la figura 2 se muestran las funciones de supervivencia de los hombres por nivel educativo y zona de residencia rural o urbana. La muestra se dividió entre hombres que no terminaron la educación secundaria, hombres que lograron culminar el bachillerato y hombres que llegan a cursar algún grado de educación superior. Los hombres más educados se unen a mayor edad que los de los otros dos grupos. Después de los 30 años de 
edad, cuando probablemente terminan su educación y definen su estatus laboral, estos aceleran el matrimonio. Sin embargo, los hombres residentes en zonas urbanas encuentran pareja más rápido que los hombres que viven en zonas rurales.

Los hombres podrían tener menores costos de búsqueda en las ciudades, así como mayores oportunidades de encontrar mujeres con mayores niveles educativos. Cuando los hombres adquieren mayor educación, sus expectativas y su utilidad de reserva aumentan. Los hombres educados de las zonas rurales se enfrentan a mercados matrimoniales en los que sus parejas potenciales son menos educadas, por lo que tienen un tiempo de soltería óptimo mayor que el de los residentes en las ciudades. Lo contrario sucede con los hombres con menores niveles educativos, quienes, si deciden retrasar el matrimonio, posteriormente aumentan sus probabilidades de quedarse solteros.

Figura 2. Funciones de supervivencia de hombres por niveles educativos y zona de residencia a los 14 años

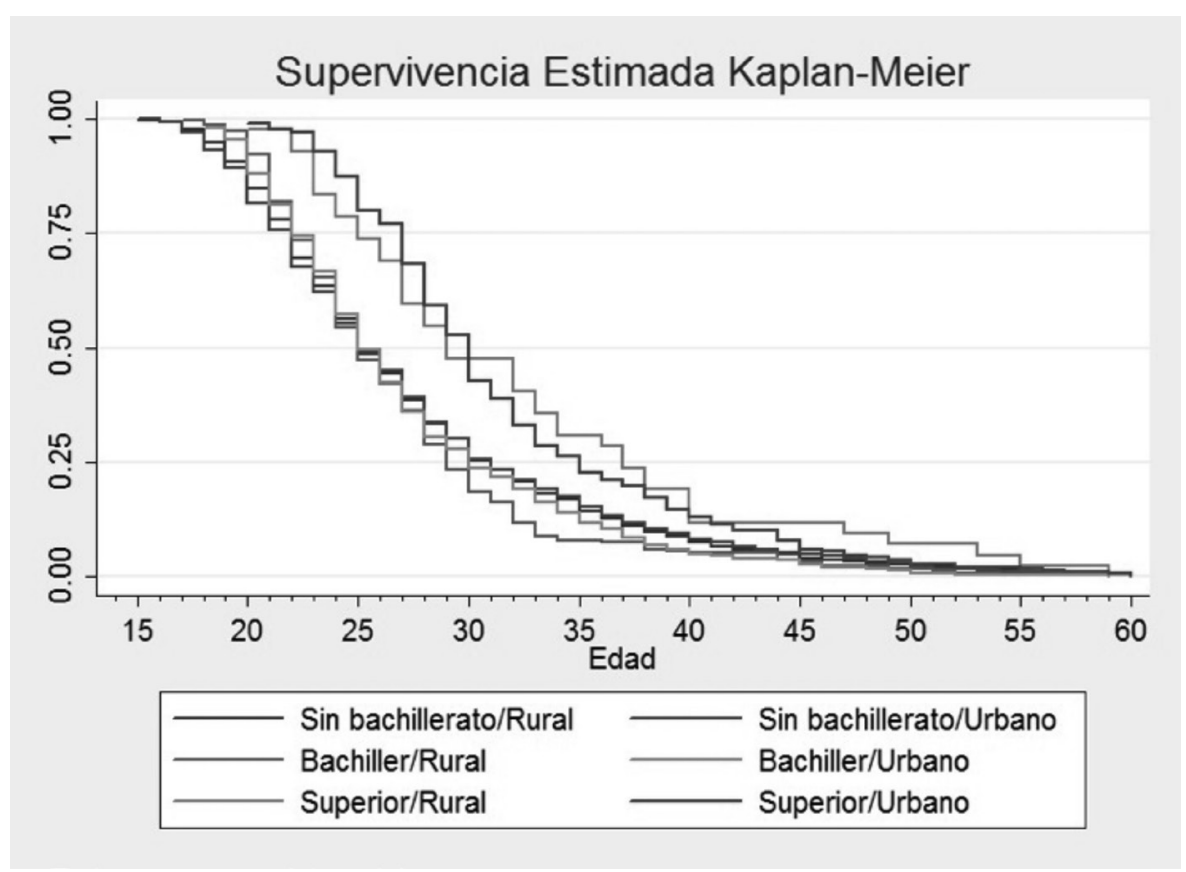

Fuente: Elaboración propia a partir de la ELCA 2010.

La función de supervivencia por niveles educativos de las mujeres muestra una historia un poco diferente, como se observa en la figura 3. A medida que las mujeres se educan más, deciden posponer las uniones conyugales, sin importar la zona de residencia. En este sentido, la mayor edad de entrada al matrimonio de las mujeres residentes en las zonas urbanas que se observa en figura 1 está muy relacionada con que tienen acceso a mayores niveles educativos. 
Diferencias de género en la edad del primer matrimonio: una evidencia desde los modelos de búsqueda marital...

A mayor nivel educativo, mayor edad de finalización de la soltería. El 50 \% de las mujeres con educación superior continúa en soltería después de los 25 años, mientras que a esa edad solo permanecen solteras el $25 \%$ de las que alcanzan solamente el bachillerato. En contraste, las mujeres con niveles educativos menores a secundaria tienen una probabilidad del $50 \%$ de unirse antes de cumplir los 21 años de edad.

Figura 3. Funciones de supervivencia de mujeres por niveles educativos y zona de residencia a los 14 años

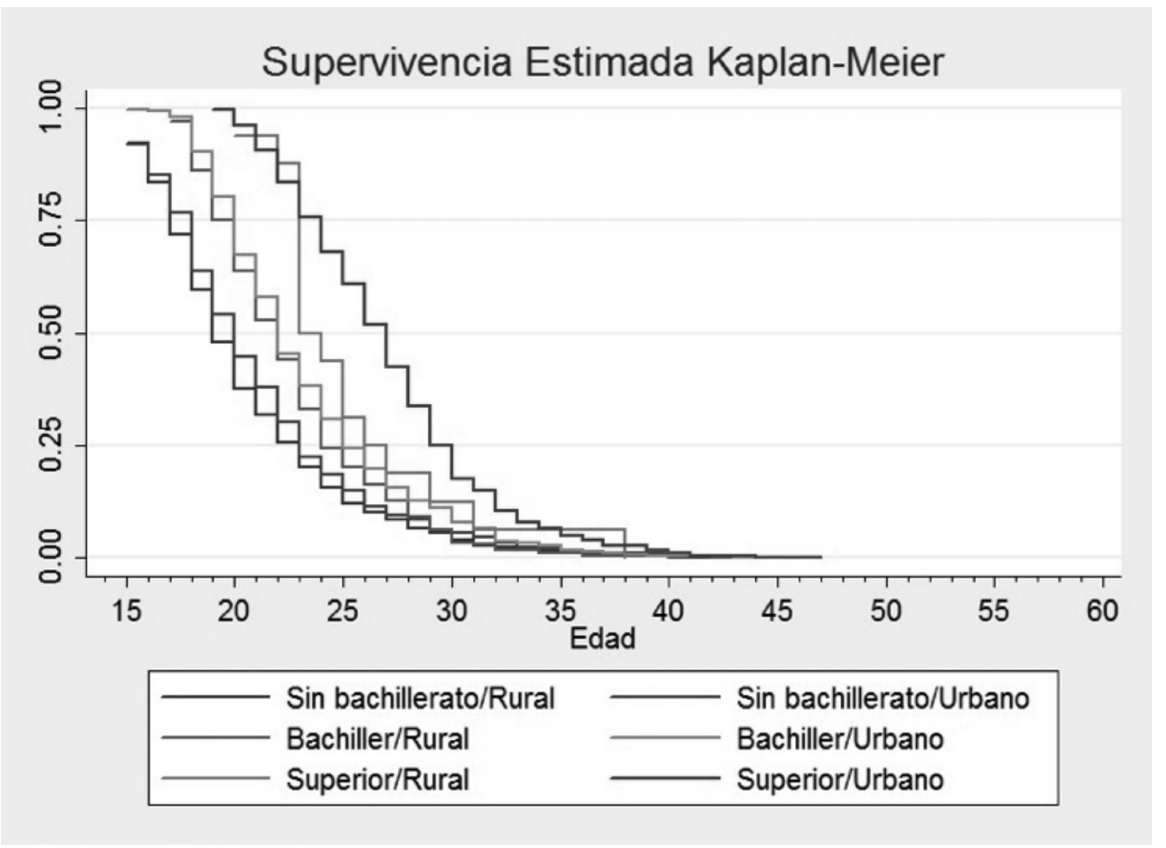

Fuente: Elaboración propia a partir de la ELCA 2010.

A medida que las mujeres alcanzan mayores niveles educativos, se observa que retrasan el matrimonio, posiblemente debido al tiempo necesario para terminar sus estudios. Una vez se completa la escolaridad, se da por terminada la transición hacia las características definitivas que explican su "valor" en el mercado matrimonial y concretan las uniones.

\subsubsection{Recursos familiares}

La figura 4 muestra las funciones de supervivencia para hombres por el nivel educativo alcanzado por su padre y madre. A los 25 años, el $50 \%$ de los hombres cuyo padre no alcanzó el nivel de educación superior ya se ha casado (línea azul), mientras que el $50 \%$ de los hombres con padres más educados espera tres años más, hasta alrededor de los 28 años (línea roja). Una posible explicación es que los ingresos del hogar están más 
relacionados con la educación del padre, quien probablemente es quien participa en el mercado laboral. Sin embargo, a partir de los 28 años, de quienes tienen ambos padres con educación superior, solo el $25 \%$ permanece soltero a los 30 años de edad.

Este resultado es consistente con los resultados de Parrado y Zenteno (2002) en el sentido de que existe una relación entre los atributos individuales y la incertidumbre acerca del desarrollo profesional más favorable. Los hombres con mayores recursos familiares (i.e. padre y madre con educación universitaria) pueden desarrollar mayores niveles de educación y tener una transición más rápida hacia mayores ingresos, que facilitan la formación de uniones. Los hombres con los hogares más educados ven mejoradas tanto sus expectativas como sus oportunidades matrimoniales en comparación con los demás. A la edad de entrada al mercado matrimonial, la disponibilidad de recursos familiares disminuye los costos intertemporales de búsqueda; después, a medida que se da el proceso de transición educativa y laboral, el proceso de encontrar parejas potenciales deseables se acelera.

Los hombres con padres educados, pero con madres sin educación superior, tienen la soltería más larga. El $25 \%$ de ellos no ha logrado conseguir una pareja aceptable hasta los 35 años de edad. Este resultado es explicado porque, por un lado, estos hombres tienen incentivos para postergar la unión conyugal en búsqueda de parejas más educadas. Sin embargo, los hombres hijos de padre y madre con educación universitaria tienen más recursos familiares y menos incertidumbre acerca de sus condiciones definitivas en comparación con este grupo, lo cual les permite conformar uniones en menor tiempo. En tal sentido, mayor incertidumbre promueve una transición más larga hacia sus características definitivas, lo que los deja con un número reducido de parejas disponibles y hace más costosa la búsqueda de pareja.

El $50 \%$ de los hombres cuyo padre no llegó a tener educación superior se casa después de los 25 años. De ellos, aquellos cuya madre tiene educación superior consiguen pareja en menor tiempo que quienes tienen padres sin nivel superior de educación. Para estos, posponer la elección de pareja implica dificultades posteriores en encontrar pareja.

Hasta antes de los 27 años de edad (figura 5), las mujeres con padre y madre que alcanzaron el nivel de educación superior son las que más posponen el matrimonio. A esa edad, alrededor del $15 \%$ de las mujeres permanece sin unirse. Sin embargo, antes de los 35 años, todas las mujeres cuyo padre tiene educación superior se han casado, mientras que las mujeres cuyo padre no tiene educación superior siguen sin casarse a edades cercanas a los 40 años. Las mujeres que más dificultades encuentran para conseguir pareja son aquellas cuyos padres alcanzaron niveles de educación superiores, mujeres que no se han casado a corta edad. Esto se observa porque su función de supervivencia (línea azul) se ubica por debajo de las de los otros grupos a medida que los años de soltería aumentan. 
Diferencias de género en la edad del primer matrimonio: una evidencia desde los modelos de búsqueda marital...

Figura 4. Funciones de supervivencia de hombres por nivel de educación de los padres

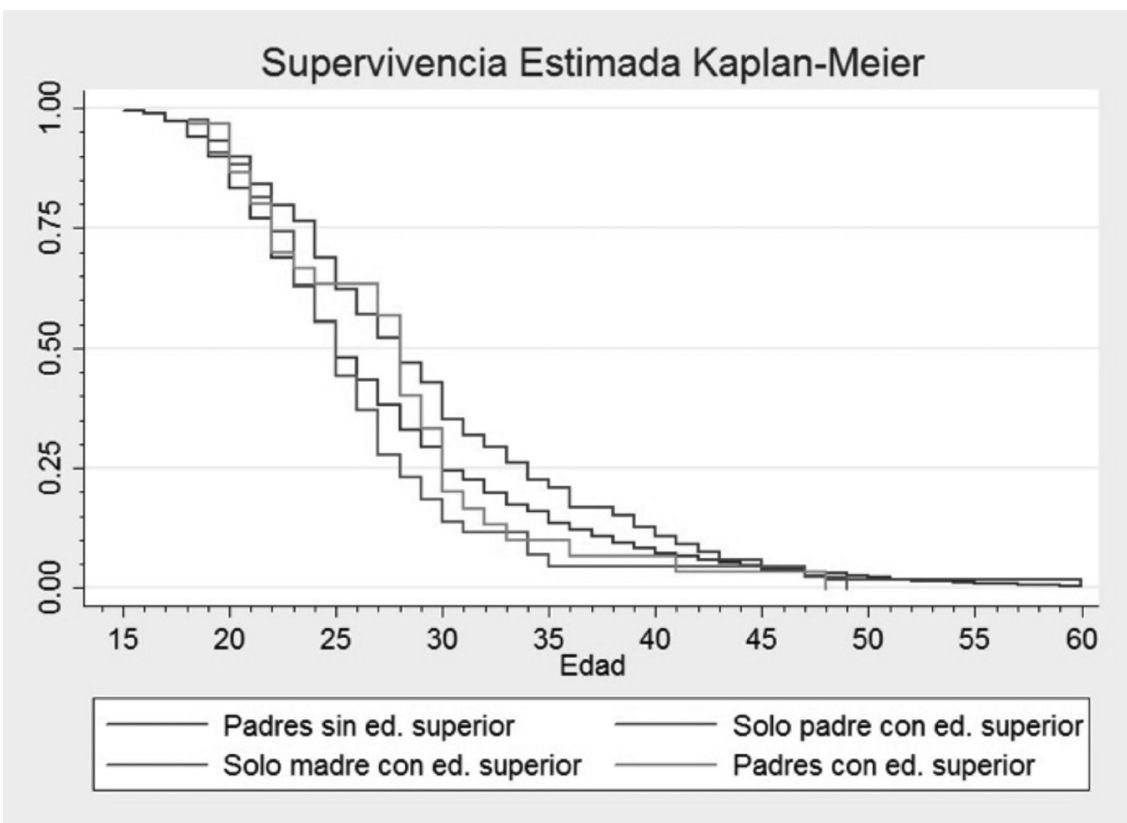

Fuente: Elaboración propia a partir de la ELCA 2010.

Figura 5. Funciones de supervivencia de mujeres por nivel de educación de los padres

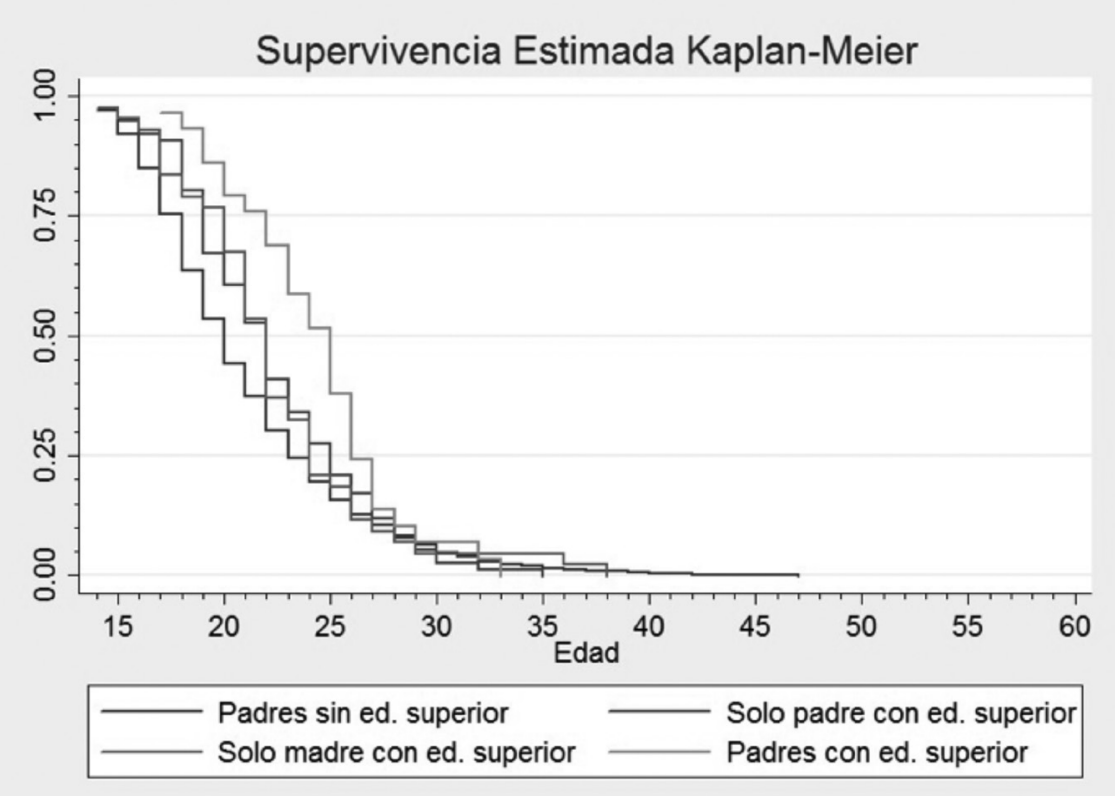

Fuente: Elaboración propia a partir de la ELCA 2010. 
Este comportamiento es coherente con los modelos de búsqueda. En presencia de emparejamiento selectivo. Más recursos implican un mayor tiempo de búsqueda, porque la calidad de las parejas potenciales aumenta a medida que estas mujeres usan los recursos familiares para acumular más capital humano y realizar la transición a su rol económico adulto. También porque la búsqueda puede resultar menos costosa para las mujeres con mayores recursos familiares.

\subsubsection{Participación laboral}

La participación laboral antes de finalizar la soltería solo se tuvo disponible para las zonas urbanas. Mientras la participación laboral masculina no tiene mayor influencia en la duración de la soltería, las mujeres que han participado en el mercado laboral posponen el matrimonio en comparación con las mujeres que nunca han trabajado.

Figura 6. Funciones de supervivencia por participación laboral y sexo

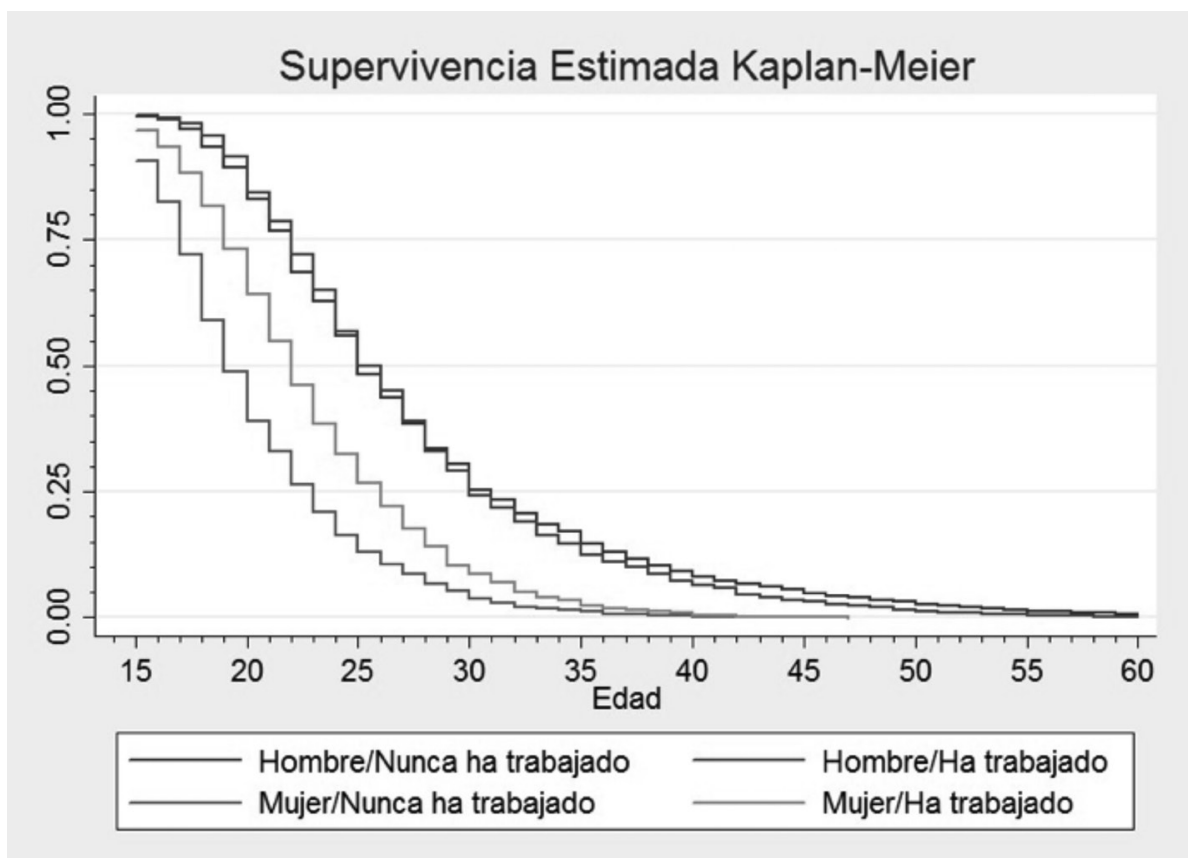

Fuente: Elaboración propia a partir de la ELCA 2010.

\subsection{Resultados del modelo de tiempo de fallo acelerado (ATF) distribuido log-logístico}

Se modela la duración de la búsqueda marital de hombres y mujeres colombianos ajustando modelos de tiempo de fallo acelerado distribuido log-logístico. La variable dependiente es el logaritmo de la edad de la primera unión conyugal (matrimonio o unión de 
hecho). Las estimaciones se realizan para hombres o mujeres entre 14 y 40 años de edad residentes en zonas urbanas ${ }^{5}$ y se incluyen efectos fijos para 21 departamentos donde vivía la persona a los 14 años.

Los resultados de las estimaciones se encuentran en la tabla 1. Para hombres y mujeres, la educación del padre aumenta el tiempo de búsqueda. Los hombres y las mujeres cuyo padre tuvo algún año de educación superior retrasan las uniones un 10,3 \% y 7,2%, respectivamente. En el caso de los hombres, la educación superior de la madre no tiene un efecto significativo en el retraso de las uniones, pero para las mujeres es de 7,5\%. Por otro lado, vivir solo a los 14 años de edad ${ }^{6}$ reduce el tiempo que los hombres duran solteros en un 5,2\%, mientras que el efecto se triplica para las mujeres, quienes apresuran las uniones un 17,9\%. Para las mujeres, vivir con personas diferentes a los padres a los 14 años de edad adelanta el matrimonio un 6,1\%, mientras que para los hombres el efecto no es significativo.

Una unidad porcentual adicional de participación laboral femenina en relación con la masculina (en el país, cuando el individuo tenía 14 años de edad) disminuye la duración de la soltería en 1,2\% para los hombres y 1,6 \% para las mujeres. Los hombres acortan su soltería $0,7 \%$ por cada unidad porcentual adicional en que se incremente el salario (promedio en el país, cuando el individuo tenía 14 años de edad) de las mujeres con respecto al de los hombres. Sin embargo, el efecto no es significativo para las mujeres. La proporción de sexos en el departamento de residencia que había cuando el individuo tenía 14 años de edad no tiene influencia sobre el tiempo de búsqueda de pareja. En términos generales, puede decirse que tanto el incremento de la participación laboral de las mujeres en relación con los hombres como su mejora relativa en salarios incentivan las uniones maritales.

Una vez hombres y mujeres finalizan los estudios o consiguen su primer trabajo, la edad a la que finalmente se casen aumentará por cada año adicional de soltería ${ }^{7}$. Para los hombres, un año adicional de soltería después de terminar los estudios incrementa 1,1 \% el tiempo en que permanecerán solteros durante toda su vida; para las mujeres, el incremento es del 1,6\%. De manera similar sucede una vez comienza la vida laboral. Por cada año adicional de soltería después de comenzar a trabajar, la edad del primer

5 En los anexos 1 y 2 se presentan las regresiones, que incluyen controles por cohortes de edad a fin de verificar la robustez de los resultados y verificar si ha habido cambios en los patrones entre diferentes cohortes de edad. Las diferencias no son significativas, sino solamente para la cohorte de menor edad, que es la que presenta mayor cantidad de datos censurados (ver anexo 1). Al excluir esta cohorte, en el anexo 2 se observa que no hay diferencias significativas entre las cohortes y que los parámetros estimados son bastante similares.

6 El porcentaje de personas que vivieron solas a los 14 años de edad es el 2,04\% de los hombres y el $1 \%$ de las mujeres. A su vez, el porcentaje que vivió a los 14 años de edad con personas distintas a los padres es $8,23 \%$ para los hombres y $10,02 \%$ para las mujeres.

7 El 10,09\% de los hombres y el 14,89 \% de las mujeres continuaron estudiando después de haberse unido. Para estos, a la variable se le asignó el valor 0 . 
matrimonio aumenta $1 \%$ para los hombres y $1,7 \%$ para las mujeres ${ }^{8}$. Una vez definidas las características de los roles económicos de hombres y mujeres, el tiempo que permanecen solteros implica unos costos de oportunidad en términos de parejas potenciales que concretan sus uniones y no quedan disponibles, por lo que cada vez debe invertirse más tiempo para encontrar parejas solteras.

La participación laboral femenina les permite postergar las uniones y a medida que los salarios iniciales son mayores, la postergación también es mayor. Comparadas con quienes no participan en el mercado laboral, las mujeres que comienzan su vida laboral ganando el salario mínimo legal postergan las uniones maritales un 7,3\%, y las que ganan más del salario mínimo lo postergan alrededor de un 10,2\% más que quienes no trabajaban antes de su primera unión ${ }^{9}$. La edad de entrada a las uniones conyugales de los hombres que inician su vida laboral ganando menos del salario mínimo legal es $6 \%$ menor que la de quienes aún no trabajan.

Los efectos de los salarios iniciales sobre la duración de la soltería pueden no ser del todo causales. Si estar unido tiene efectos sobre la riqueza, los hombres y las mujeres casados que no están en el mercado laboral podrían tener incentivos para entrar en el mercado laboral después de casados. Por otro lado, esta variable también tiene cierto nivel de carácter endógeno derivado del hecho de que, al momento en que se determina la variable dependiente, esta variable también se está afectando para la parte de la población que no ha empezado a trabajar.

La educación y la participación laboral aumentan el poder de negociación de la mujer. En este sentido, las mujeres casadas o con alta probabilidad de casarse tienen incentivos adicionales a los del mercado laboral para educarse y participar en el mercado laboral, incentivos relacionados con el mercado matrimonial. En tal caso, no se pueden hacer inferencias causales acerca de la relación entre el mercado laboral, el capital humano y la duración de la soltería entre quienes tienen variables no observadas que inciden sobre la utilidad de tener educación y entrar en el mercado laboral después de haberse casado.

Finalmente, el parámetro Gamma, que se refiere a la forma de la distribución log-logística, indica que la probabilidad de casarse comienza siendo creciente a edades tempranas y posteriormente se hace decreciente. Al $1 \%$ de significancia este parámetro es menor que 1. Este resultado tiene implicaciones para este estudio porque conlleva que la probabilidad instantánea de formar una unión decrece después de cierta edad, por lo que los individuos que posponen la unión más allá de cierta edad tienen cada vez menos probabilidades de conseguir pareja. Se utiliza a continuación el modelo estimado para

8 Mientras solamente el 2,3\% de los hombres comienza a trabajar después de unirse, el 9,8\% de las mujeres empieza su vida laboral después de haberse unido. Para estos individuos, la variable se codificó con el valor 0 .

9 El porcentaje de individuos que no trabajaron antes de su primera unión es el 2,51 \% de los hombres y el 10,12\% de las mujeres. 
Diferencias de género en la edad del primer matrimonio: una evidencia desde los modelos de búsqueda marital...

predecir la probabilidad de cambiar de estado de soltero a casado o en unión de hecho a cada edad y se muestran varios perfiles de duración que ilustran el comportamiento de la función de riesgo.

Tabla1. Modelo ATF estimado mediante regresión log-logística

\begin{tabular}{|c|c|c|}
\hline \multicolumn{3}{|c|}{ Variable dependiente: Logaritmo de la edad de la primera unión marital } \\
\hline & Hombres & Mujeres \\
\hline \multicolumn{3}{|l|}{$\begin{array}{l}\text { Status socioeconómico y recursos familiares } \\
\text { (Ref. Sin años de educación superior) }\end{array}$} \\
\hline Educación superior padre & $\begin{array}{l}0,103^{* *} \\
(0,020)\end{array}$ & $\begin{array}{c}0,072^{* *} \\
(0,022)\end{array}$ \\
\hline Educación superior madre & $\begin{array}{l}-0,035 \\
(0,037)\end{array}$ & $\begin{array}{c}0,075^{* *} \\
(0,028)\end{array}$ \\
\hline $\begin{array}{l}\text { (Ref. Vivía con alguno de sus padres) } \\
\text { Personas diferentes }\end{array}$ & $\begin{array}{l}-0,025 \\
(0,017)\end{array}$ & $\begin{array}{c}-0,061^{* *} \\
(0,020)\end{array}$ \\
\hline Vivía solo & $\begin{array}{c}-0,052+ \\
(0,031)\end{array}$ & $\begin{array}{c}-0,179 * * \\
(0,058)\end{array}$ \\
\hline \multicolumn{3}{|c|}{ Características de los mercados laborales/matrimoniales a los 14 años } \\
\hline Proporción de sexos & $\begin{array}{l}0,108 \\
(0,152)\end{array}$ & $\begin{array}{l}-0,286 \\
(0,199)\end{array}$ \\
\hline Participación laboral mujeres & $\begin{array}{c}-0,012^{* *} \\
(0,004)\end{array}$ & $\begin{array}{c}-0,016^{* *} \\
(0,005)\end{array}$ \\
\hline Brecha salarial & $\begin{array}{c}-0,007 * * \\
(0,002)\end{array}$ & $\begin{array}{l}-0,000 \\
(0,003)\end{array}$ \\
\hline \multicolumn{3}{|c|}{ Indicadores de transición individual a la adultez } \\
\hline Años desde que dejo/terminó estudios & $\begin{array}{c}0,011 * * \\
(0,001)\end{array}$ & $\begin{array}{r}0,016^{* *} \\
(0,002)\end{array}$ \\
\hline Años desde que trabajó por primera vez & $\begin{array}{l}0,010 * * \\
(0,001)\end{array}$ & $\begin{array}{r}0,017 * * \\
(0,002)\end{array}$ \\
\hline \multicolumn{3}{|c|}{ Salario inicial (Ref. No había trabajado antes de su primera unión) } \\
\hline Menos del mínimo & $\begin{array}{c}-0,060^{* * *} \\
(0,012)\end{array}$ & $\begin{array}{l}-0,004 \\
(0,017)\end{array}$ \\
\hline El mínimo & $\begin{array}{l}-0,016 \\
(0,013)\end{array}$ & $\begin{array}{c}0,073 * * \\
(0,015)\end{array}$ \\
\hline Más del mínimo & $\begin{array}{c}0,017 \\
(0,019)\end{array}$ & $\begin{array}{c}0,102^{* *} \\
(0,029)\end{array}$ \\
\hline
\end{tabular}




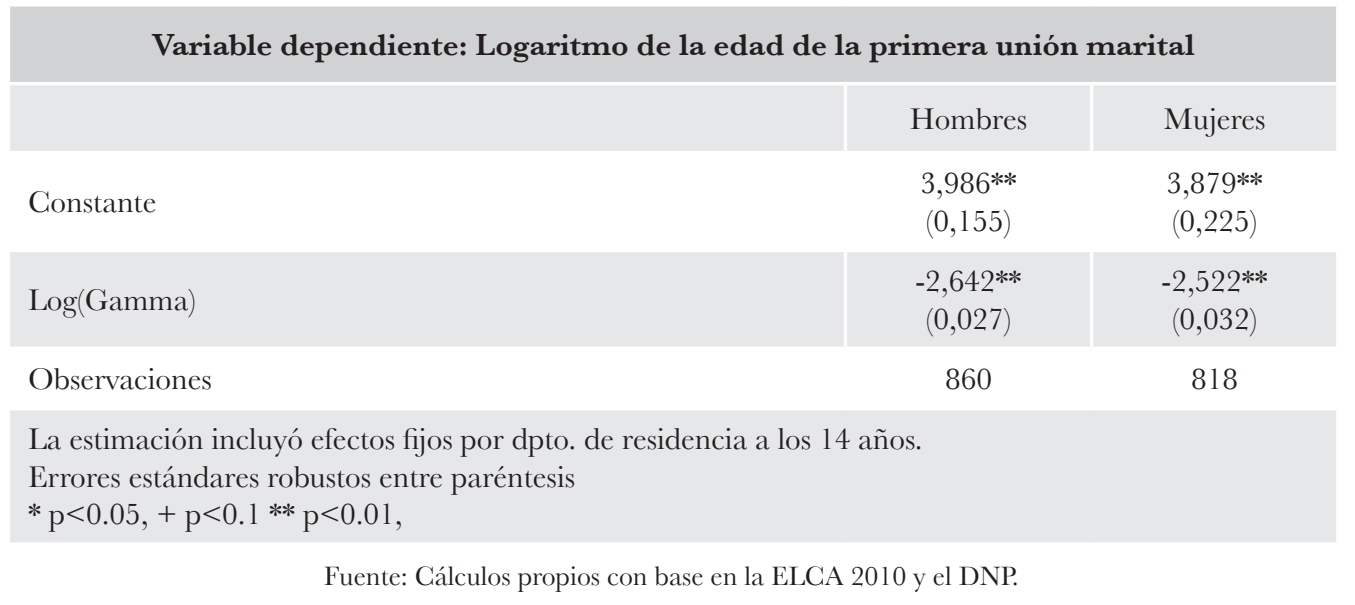

\subsubsection{Perfiles de duración}

A partir de los parámetros estimados, se predice la probabilidad de finalizar la soltería para hombres y mujeres, dados los valores específicos de las variables explicativas y manteniendo las otras variables en sus valores promedios. En cada uno se muestra que, después de cierta edad, la probabilidad de unirse es cada vez menor, que las personas con mejores condiciones pueden prolongar la soltería por más tiempo y que su probabilidad de unirse, aunque es menor, decae más lentamente que para las personas en peores condiciones.

Figura 7. Probabilidad estimada de los hombres de finalizar la

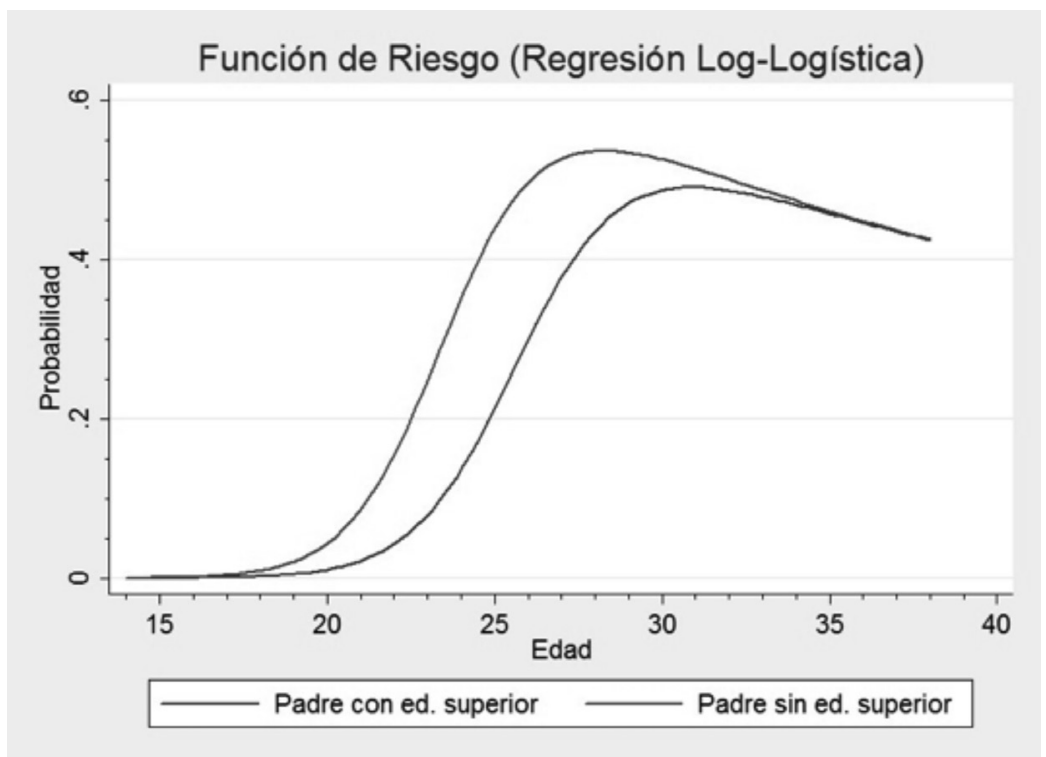

Fuente: Elaboración propia a partir de la ELCA 2010 y el DNP. 
Diferencias de género en la edad del primer matrimonio: una evidencia desde los modelos de búsqueda marital...

Figura 8. Probabilidad estimada para las mujeres de finalizar la soltería por nivel educativo alcanzado por el padre

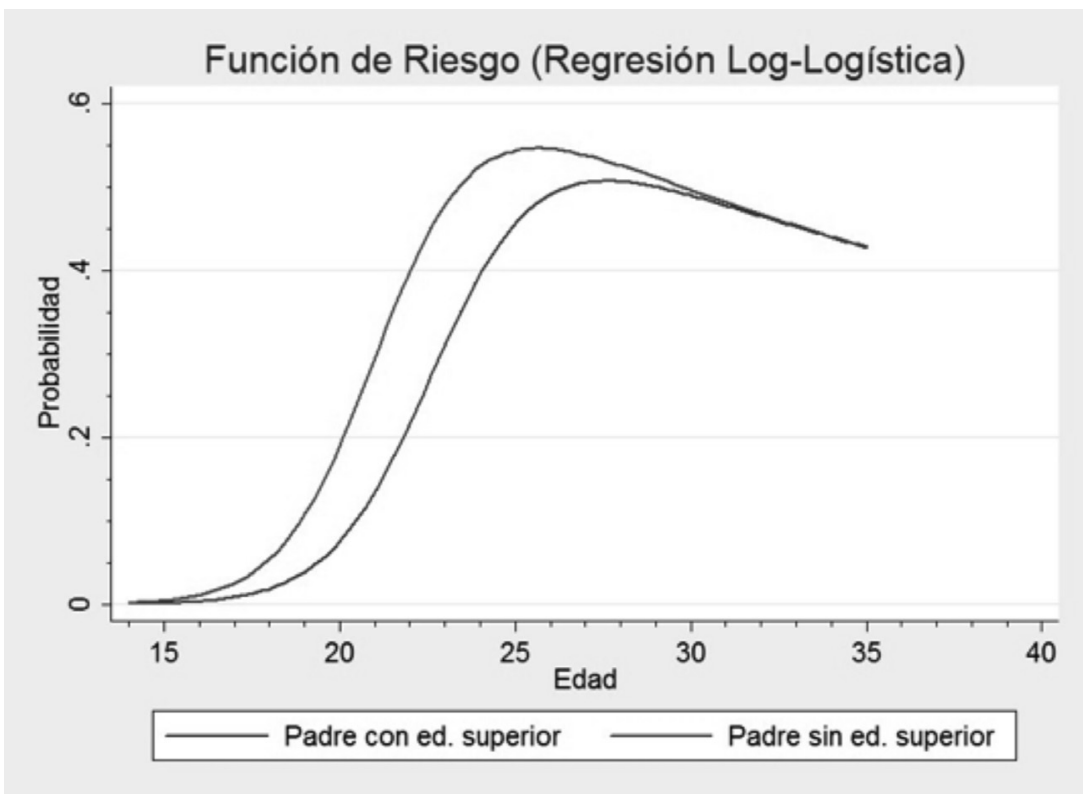

Fuente: Elaboración propia a partir de la ELCA 2010 y el DNP.

Figura 9. Probabilidad estimada de los hombres de finalizar la soltería por nivel de salarios relativos de mujeres vs. hombres

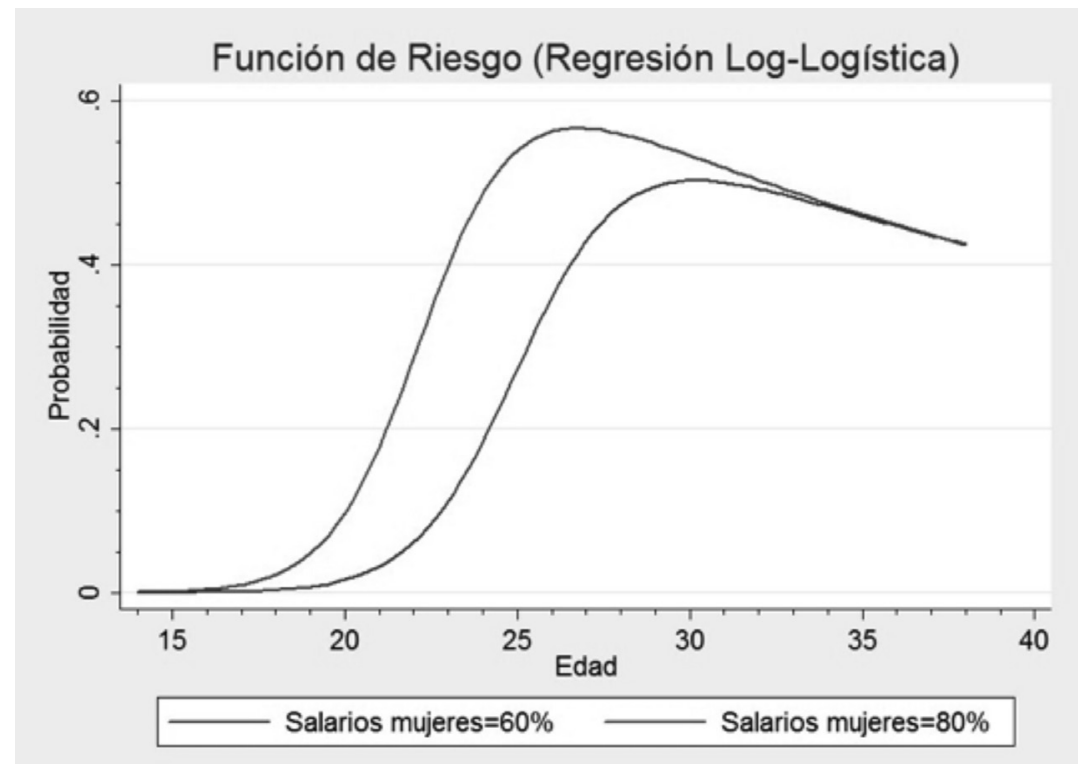

Fuente: Elaboración propia a partir de la ELCA 2010 y el DNP. 
Figura 10. Probabilidad estimada de los hombres de finalizar la soltería por nivel de salarios de entrada al mercado laboral

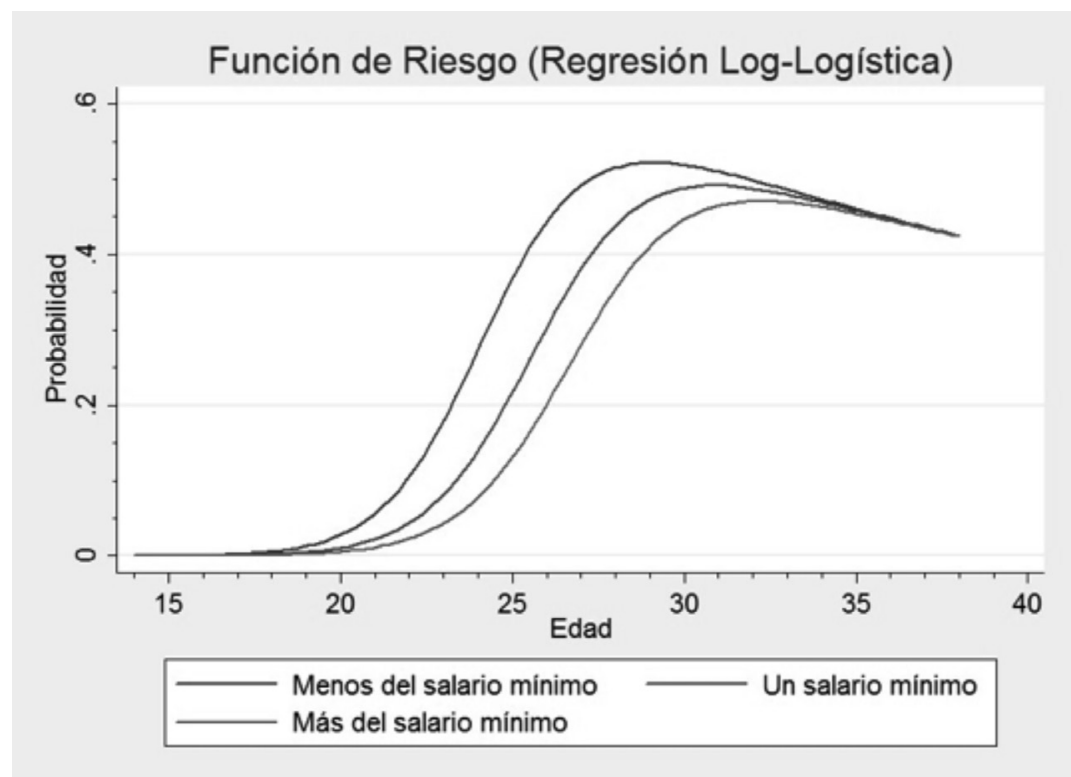

Fuente: Elaboración propia a partir de la ELCA 2010 y el DNP.

Figura 11. Probabilidad estimada de las mujeres de finalizar la soltería por nivel de salarios de entrada al mercado laboral

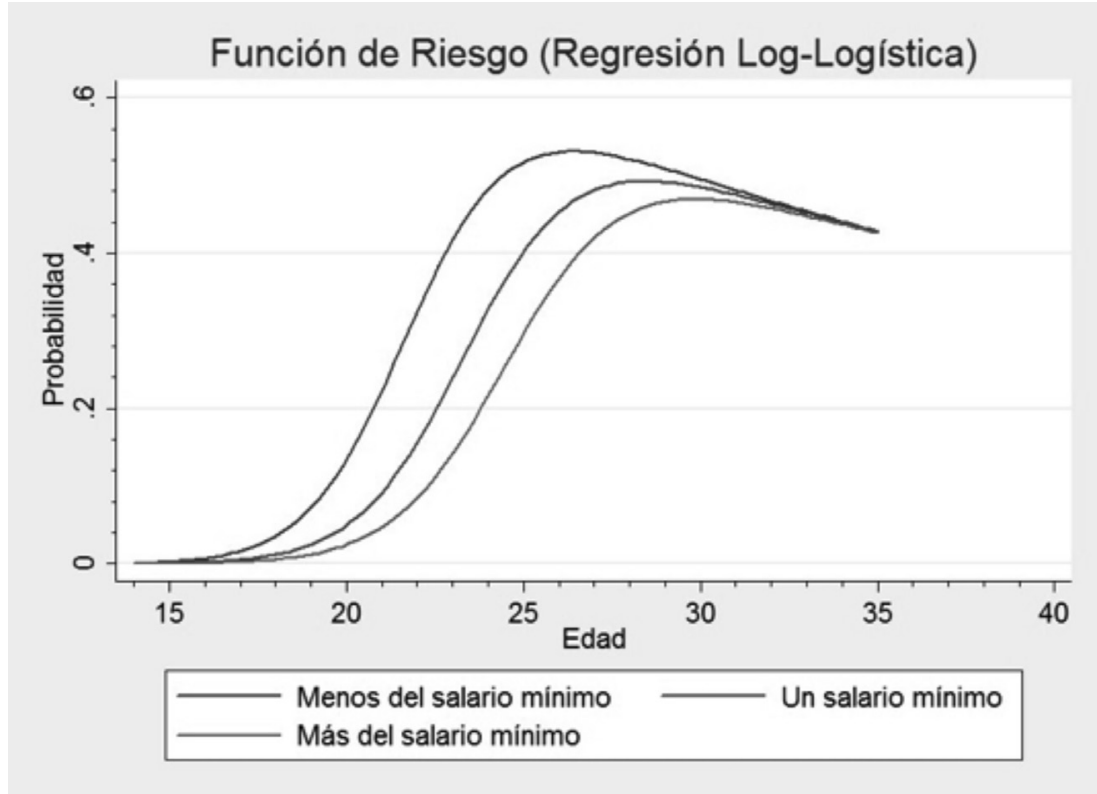

Fuente: Elaboración propia a partir de la ELCA 2010 y el DNP. 
Diferencias de género en la edad del primer matrimonio: una evidencia desde los modelos de búsqueda marital...

\section{Conclusiones}

Como predicen las teorías económicas del matrimonio, los colombianos deciden emparejarse selectivamente. Este hecho se constata en la medida en que los individuos con mayores recursos familiares y en entornos familiares que favorecen la acumulación de capital humano se toman más tiempo para buscar pareja. Sin embargo, la evidencia descriptiva y el comportamiento de la tasa de riesgo estimada sugieren que, una vez finalizada la transición hacia los niveles definitivos de educación y la entrada al mercado laboral, rápidamente los individuos se emparejan. Es de resaltar que la estructura familiar a los 14 años de edad afecta sustancialmente más a las mujeres que a los hombres.

La duración de la soltería y la probabilidad de unirse conyugalmente en los hombres y mujeres colombianos dependen de características del entorno familiar que reducen la incertidumbre acerca de las perspectivas, ya sean favorables o desfavorables, de su posterior estatus económico. Por otra parte, la probabilidad de unirse a determinada edad para las mujeres colombianas está determinada por la mejora de su estatus económico, que incentiva a los hombres a unirse a ellas porque el ingreso femenino adicional permite tener hogares más ricos en menor tiempo. En este orden de ideas, el ingreso y la participación laboral femenina complementan, en lugar de sustituir, los de sus parejas e incentivan la conformación de familias.

Como predicen los modelos de búsqueda, las personas con mayor acceso a la educación, hombres y mujeres, posponen el matrimonio, pero no necesariamente porque los incentivos para formar pareja disminuyan. En realidad, a medida que los individuos superan la transición hacia sus roles económicos adultos, la velocidad a la que abandonan el estado de soltería permite que, en unos años, la población en su totalidad tenga algún tipo de unión, mientras que los de menores recursos y menos educados tienen un largo periodo se soltería hasta avanzadas edades.

Los individuos con menores recursos familiares, niveles de educación y menores salarios de entrada se unen, ya sea en matrimonio o unión de hecho, a menor edad porque su transición a los niveles definitivos de estas características es más corta. De hecho, a medida que pasa el tiempo, sus posibilidades de conseguir pareja son menores que las de las personas más ricas. En consecuencia, el comportamiento matrimonial, que muchas veces se argumenta como causa de menor riqueza familiar en el futuro, puede ser resultado precisamente de criarse en hogares con pocos recursos en donde el comportamiento óptimo de los individuos surge de elegir entre emparejarse a edades tempranas o enfrentarse a grandes dificultades para formar una familia después. Por otro lado, si quienes se unen a menor edad tienen una mayor fertilidad, entonces estos hogares no solo tienen mayor número de hijos, sino que poseen menos recursos para invertir en ellos. 
Debido a las restricciones de los datos, este estudio no permite obtener resultados sobre las personas cuya primera unión finalizó antes de ser encuestadas, esto debido a que no es posible establecer la edad a la que comenzó dicha unión. Esta restricción afecta la inferencia de los resultados de este estudio en la medida en que la muestra se encuentra condicionada por las características que aumentan la estabilidad de las uniones de pareja. Por lo tanto, la generalización de estas conclusiones es limitada. En la medida en que la estabilidad de los matrimonios se encuentre relacionada con mayores ganancias de encontrarse en pareja, los efectos de las variables explicativas podrían estar sobreestimando o subestimando los de toda la población y representar solamente los efectos de las variables explicativas sobre quienes tienen uniones con menores probabilidades de romperse.

A su vez, sería de interés para estudios posteriores verificar los resultados para una muestra de individuos en las zonas rurales, con el objetivo de contrastar las posibles diferencias en la magnitud y significancia por zonas. Finalmente, la interacción y la retroalimentación entre las decisiones educativas, de participación laboral y de estatus matrimonial han sido poco exploradas. En esta medida, en trabajos posteriores se podrán establecer relaciones causales entre la educación, los salarios y la decisión de establecer un hogar.

\section{Referencias}

Amador, D., Bernal, R. y Peña, X. (2013). The rise in female participation in Colombia: Fertility, marital status or education. Ensayos sobre Política Económica, 13(71). Recuperado de goo.gl/WN6Gw9

Angrist, J. (2002). How do sex ratios affect marriage and labor markets? Evidence from America's second generation. The Quarterly fournal of Economics, 117(3), 997-1038.

Becker, G. (1973). A theory of marriage. Fournal of Political Economy, 81(4), 813-846. . (1991). A treatise on the family. London: Harvard University Press.

Becker, G., Landes, E., \& Michael, R. (1977). An economic analysis of marital instability. Fournal of Political Economy, 85(6), 1141-1187.

Blossfeld, H-P., \& Huinik, J. (1991). Human capital investments or norms of role transition? How women's schooling and career affect the process of family formation. American fournal of Sociology, 97(1), 143-168. Recuperado de goo.gl/3Bcdgl

Boulier, B. L., \& Rosenzweig, M. R. (1984). Schooling, search, and spouse selection: Testing economic theories of marriage and household. Fournal of Political Economy, 92(4), 712-732. 
Diferencias de género en la edad del primer matrimonio: una evidencia desde los modelos de búsqueda marital...

Bracher, M., \& Santow, G. (1998). Economic independence and union formation in Sweden. Population Studies, 52(3), 275-294.

Cox, D. R. (1972). Regression Models and Life-Tables. Fournal of the Royal Statistical Society (Series B. Methodological), 34(2), 187-220. Recuperado de http://www.biecek.pl/statystykaMedyczna/cox.pdf

Fafchamps, M., \& Quisumbing, A. R. (2007). Household formation and marriage markets in rural areas. En T. P. Schultz \& J. Strauss, Handbook of Development Economics (1.a ed., vol. IV, pp. 3187-3247). Amsterdam: Elsevier. Recuperado de https://web. stanford.edu/ fafchamp/handbl.pdf

Goldstein, J. R., \& Kenney, K. T. (2001). Marriage delayed or marriage forgone? New cohort forecasts of first marriage for U.S. women. American Sociological Review, 66(4), 506-519.

Jordán Quintero, M. V. (2006). ¿Quién con quién? Movilidad social y unión semejante, evidencia para el caso colombiano (Documento CEDE, 44). Bogotá: Universidad de los Andes. Recuperado de goo.gl/QODGmS

Lehrer, E. (2006). Age at marriage and marital instability (Discussion Paper Series). Bonn: Institute for the Study of Labor (IZA). Recuperado de http://repec.iza.org/dp2166. pdf

Lewis, S. K., \& Oppenheimer, V. K. (2000). Educational assortative mating across marriage markets: Non-hispanic whites in the United States. Demography, 37(1), 29-40.

Manda, S., \& Meyer, R. (2005). Age at first marriage in Malawi: A bayesian multilevel analysis using a Discrete Time-to-Event Model. Fournal of the Royal Statistical Society, $168(2), 439-455$.

Montgomery, M., \& Trussell, J. (1986). Models of marital status and childbearing. En O. C. Ashenfelter \& R. Layard (eds.), Handbook of Labor Economics (1.a ed., vol. I, pp. 201-271). Amasterdam: Elsevier.

Nobles, J., \& Buttenheim, A. (2008). Marriage and socioeconomic change in contemporary Indonesia. Journal of Marriage and Family, 70(4), 904-918.

Ono, H. (2003). Women's economic standing, marriage timing, and cross-national contexts of gender. Journal of Marriage and Family, 65(2), 275-286.

Oppenheimer, V. K. (1988). A theory of marriage timing. American Fournal of Sociology, 94(3), 563-591. 
. (1997). Women's employment and the gain to marriage: The specialization and Trading Model. Annual Review of Sociology, 23, 431-453.

Parrado, E. A., \& Zenteno, R. M. (2002). Gender differences in union formation in México: evidence from marital search models. Fournal of Marriage and Family, 64(3), 756-773.

Peña, X. (2006). Assortative matching and the education gap. Borradores de Economía, 427. Recuperado de goo.gl/7nDgsY

Peña, X., Cárdenas, J., Ñopo, H., Castañeda, J., Muñoz, S. y Uribe, C. (2013). Mujer y movilidad social (Series Documentos CEDE). Bogotá: Universidad de los Andes. Recuperado de goo.gl/YTXMxn

Piñeros, L. A. (2009). Las uniones maritales, los diferenciales salariales y la brecha educativa en Colombia. Desarrollo y Sociedad, 64, 55-84. Recuperado de http://www.redalyc.org/articulo.oa?id=169115615002

Quisumbing, A. R., \& Hallman, K. (2003). Marriage in transition: Evidence on age, education, and assets from six developing countries (Policy Research Division Working Paper 183). New York: Population Council, Policy Research Division.

Santow, G., \& Bracher, M. (1994). Change and continuity in the formation of first marital unions in Australia. Population Studies, 48(3), 475-496.

Shemyakina, O. (2011). The marriage market and Tajik armed conflict (HiCN Working Paper 66). Atlanta: The Institute of Development Studies. Recuperado de goo.gl/8e6hEa

Tenjo, J., Misas, M., Contreras, A. y Gaviria, A. (2012). Modelos de duración del desempleo en Colombia. Bogotá D. C.: Pontificia Universidad Javeriana. Recuperado de goo. $\mathrm{gl} / 3 \mathrm{D} 4 \mathrm{ZcH}$ 
Diferencias de género en la edad del primer matrimonio: una evidencia desde los modelos de búsqueda marital...

\section{Anexos}

\section{Anexo 1. Regresión Log-Logística incluyendo variables dicótomas de cohortes de edad}

\begin{tabular}{|c|c|c|}
\hline \multicolumn{3}{|c|}{ Regresión Log-Logística incluyendo variables dicótomas de cohortes de edad } \\
\hline & Hombres & Mujeres \\
\hline \multicolumn{3}{|l|}{$\begin{array}{l}\text { Status socioeconómico y recursos familiares } \\
\text { (Ref. Sin años de educación superior) }\end{array}$} \\
\hline Educación superior padre & $\begin{array}{c}0,100 * * \\
(0,022)\end{array}$ & $\begin{array}{c}0,067 * * \\
(0,022)\end{array}$ \\
\hline Educación superior madre & $\begin{array}{l}-0,038 \\
(0,038)\end{array}$ & $\begin{array}{c}0,064 * * \\
(0,024)\end{array}$ \\
\hline $\begin{array}{l}\text { (Ref. Vivía con alguno de sus padres) } \\
\text { Personas diferentes }\end{array}$ & $\begin{array}{l}-0,023 \\
(0,016)\end{array}$ & $\begin{array}{c}-0,062 * * \\
(0,021)\end{array}$ \\
\hline Vivía solo & $\begin{array}{l}-0,048 \\
(0,036)\end{array}$ & $\begin{array}{c}-0,167 * * \\
(0,059)\end{array}$ \\
\hline \multicolumn{3}{|c|}{ Características de los mercados laborales/matrimoniales a los 14 años } \\
\hline Proporción de sexos & $\begin{array}{c}0,012 \\
(0,156)\end{array}$ & $\begin{array}{l}-0,260 \\
(0,220)\end{array}$ \\
\hline Participación laboral mujeres & $\begin{array}{l}-0,003 \\
(0,007)\end{array}$ & $\begin{array}{c}-0,020^{*} \\
(0,008)\end{array}$ \\
\hline Brecha salarial & $\begin{array}{c}-0,008 * * \\
(0,002)\end{array}$ & $\begin{array}{l}-0,003 \\
(0,003)\end{array}$ \\
\hline \multicolumn{3}{|c|}{ Indicadores de transición individual a la adultez } \\
\hline Años desde que dejo/terminó estudios & $\begin{array}{c}0,010 * * \\
(0,001)\end{array}$ & $\begin{array}{c}0,013 * * \\
(0,002)\end{array}$ \\
\hline Años desde que trabajó por primera vez & $\begin{array}{c}0,010^{* *} \\
(0,001)\end{array}$ & $\begin{array}{c}0,016^{* *} \\
(0,002)\end{array}$ \\
\hline
\end{tabular}

Salario inicial (Ref. No había trabajado antes de su primera unión)

\begin{tabular}{|l|c|c}
\hline Menos del mínimo & $-0,050 * *$ & $-0,001$ \\
& $(0,012)$ & $(0,017)$ \\
\hline El mínimo & $-0,008$ & $0,073^{* *}$ \\
& $(0,013)$ & $(0,015)$ \\
\hline Más del mínimo & 0,010 & $0,100^{* *}$ \\
& $(0,019)$ & $(0,028)$
\end{tabular}




\begin{tabular}{|c|c|c|}
\hline \multicolumn{3}{|c|}{ Variable dependiente: Logaritmo de la edad de la primera unión marital } \\
\hline & Hombres & Mujeres \\
\hline Edad $<20$ & $\begin{array}{c}-0,146^{* * *} \\
(0,048)\end{array}$ & $\begin{array}{c}-0,009 \\
(0,055)\end{array}$ \\
\hline $20<$ edad $<25$ & $\begin{array}{l}-0,050 \\
(0,041)\end{array}$ & $\begin{array}{c}0,033 \\
(0,050)\end{array}$ \\
\hline $25<$ edad $<30$ & $\begin{array}{c}0,005 \\
(0,023)\end{array}$ & $\begin{array}{c}0,020 \\
(0,029)\end{array}$ \\
\hline $30<$ edad $<35$ & $\begin{array}{l}-0,013 \\
(0,018)\end{array}$ & $\begin{array}{c}0,011 \\
(0,020)\end{array}$ \\
\hline Constante & $\begin{array}{c}3,488 * * \\
(0,274)\end{array}$ & $\begin{array}{c}3,782^{* *} \\
(0,355)\end{array}$ \\
\hline Log(Gamma) & $\begin{array}{c}-2,743^{* *} \\
(0,029)\end{array}$ & $\begin{array}{c}-2,579 * * \\
(0,032)\end{array}$ \\
\hline Observaciones & 757 & 778 \\
\hline \multicolumn{3}{|c|}{$\begin{array}{l}\text { La estimación incluyó efectos fijos por dpto. de residencia a los } 14 \text { años. } \\
\text { Errores estándar robustos entre paréntesis. } \\
* \mathrm{p}<0.05,+\mathrm{p}<0.1 * * \mathrm{p}<0.01\end{array}$} \\
\hline
\end{tabular}

\section{Anexo 2. Regresión Log-Logística incluyendo variables dicótomas de cohortes de edad y excluyendo la cohorte de menores de 20 años}

\section{Regresión Log-Logística incluyendo variables dicótomas de cohortes de edad y excluyendo la cohorte de menores de 20 años}

Hombres

Mujeres

Status socioeconómico y recursos familiares

(Ref. Sin años de educación superior)

Educación superior padre

\begin{tabular}{c|c}
\hline $0,100^{* *}$ & $0,074^{* *}$ \\
$(0,024)$ & $(0,023)$ \\
$-0,037$ & $0,069^{* *}$ \\
$(0,041)$ & $(0,024)$
\end{tabular}

Educación superior madre

(Ref. Vivía con alguno de sus padres)

Personas diferentes

Vivía solo
$-0,022$

\begin{tabular}{c|c}
$-0,022$ & $-0,069 * *$ \\
$(0,016)$ & $(0,022)$ \\
\hline
\end{tabular}

$-0,048$

$(0,037)$

$(0,067)$ 
Diferencias de género en la edad del primer matrimonio: una evidencia desde los modelos de búsqueda marital...

\section{Regresión Log-Logística incluyendo variables dicótomas de cohortes de edad y excluyendo la cohorte de menores de 20 años}

\section{Hombres \\ Mujeres}

Características de los mercados laborales/matrimoniales a los 14 años

\begin{tabular}{|c|c|c|}
\hline Proporción de sexos & $\begin{array}{c}0,002 \\
(0,164)\end{array}$ & $\begin{array}{l}-0,175 \\
(0,247)\end{array}$ \\
\hline Participación laboral mujeres & $\begin{array}{l}-0,003 \\
(0,008)\end{array}$ & $\begin{array}{c}-0,021 * \\
(0,008)\end{array}$ \\
\hline Brecha salarial & $\begin{array}{c}-0,007 * * \\
(0,002)\end{array}$ & $\begin{array}{c}-0,003 \\
(0,003)\end{array}$ \\
\hline
\end{tabular}

Indicadores de transición individual a la adultez

Años desde que dejo/terminó estudios

Años desde que trabajó por primera vez

Salario inicial (Ref. No había trabajado antes de su primera unión)

\begin{tabular}{|c|c|c|}
\hline Menos del mínimo & $\begin{array}{c}-0,049 * * \\
(0,013)\end{array}$ & $\begin{array}{l}-0,005 \\
(0,018)\end{array}$ \\
\hline El mínimo & $\begin{array}{l}-0,006 \\
(0,013)\end{array}$ & $\begin{array}{c}0,076 \text { ** } \\
(0,016)\end{array}$ \\
\hline Más del mínimo & $\begin{array}{c}0,011 \\
(0,019)\end{array}$ & $\begin{array}{c}0,103^{* *} \\
(0,028)\end{array}$ \\
\hline $20<$ edad $<25$ & $\begin{array}{l}-0,048 \\
(0,041)\end{array}$ & $\begin{array}{c}0,040 \\
(0,050)\end{array}$ \\
\hline $25<$ edad $<30$ & $\begin{array}{c}0,006 \\
(0,024)\end{array}$ & $\begin{array}{c}0,025 \\
(0,029)\end{array}$ \\
\hline $30<$ edad $<35$ & $\begin{array}{l}-0,013 \\
(0,018)\end{array}$ & $\begin{array}{c}0,011 \\
(0,020)\end{array}$ \\
\hline Constante & $\begin{array}{c}3,486 * * \\
(0,279)\end{array}$ & $\begin{array}{c}3,712^{* *} \\
(0,376)\end{array}$ \\
\hline $\log ($ Gamma $)$ & $\begin{array}{c}2,834 * * \\
(0,037)\end{array}$ & $\begin{array}{c}-2,558 * * \\
(0,018)\end{array}$ \\
\hline Observaciones & 740 & $(0,033)$ \\
\hline
\end{tabular}


